\title{
In Silico Investigation of Propolis Compounds as Potential Neuroprotective Agent
}

\author{
Putri Hawa Syaifie ${ }^{1, *(\mathbb{D}}$, Andjani Widya Hemasita ${ }^{2}$, Dwi Wahyu Nugroho ${ }^{1,4} \mathbb{D}$, Etik Mardliyati ${ }^{1,3}$, Isa \\ Anshori 2,*iD \\ 1. Nano Center Indonesia, Jl. PUSPIPTEK, South Tangerang, Banten, 15314, Indonesia \\ 2. Biomedical Engineering Department, Bandung Institute of Technology, Bandung 40132, Indonesia \\ 3. Center for Pharmaceutical and Medical Technology, National Research and Innovation Agency, PUSPIPTEK, South \\ Tangerang, Banten, 15314, Indonesia \\ 4. Industrial Engineering Department, University of Nahdlatul Ulama Indonesia, Jakarta, 10430, Indonesia \\ * Correspondence: putri@nano.or.id (P.H.S.); isaa@ staff.stei.itb.ac.id (I.A.); \\ Scopus Author ID 57218891632 (P.H.S.); 57218315269 (I.A.)
}

Received: 19.10.2021; Revised: 15.11.2021; Accepted: 19.11.2021; Published: 10.12.2021

\begin{abstract}
Alzheimer's disease is a neurodegenerative disorder caused by several factors, namely neuroinflammation, neuronal apoptosis, and low levels of neurotransmitter Acetylcholine. MAPK14, TNF- $\alpha$, IL- $1 \beta$, and NF-KB are proteins that are directly involved in the neuroinflammatory signaling pathway. Caspase 3 is involved in neuronal apoptosis, and AChE act as a neurotransmitter breakdown catalyst. In this study, docking analysis of propolis compounds was successfully done against six proteins related neurodegenerative. The results show that 18 compounds of propolis have a better binding affinity than standard drugs (donepezil, huperzine A, fostamatinib, and amrinone). For AChE, only isoetin has a lower binding affinity than donepezil. Isoetin was also observed to inhibit the Caspase3, MAPK14, NF-kB, and TNF- $\alpha$. In silico prediction of the blood-brain barrier (BBB) permeant revealed that three propolis compounds could pass the $\mathrm{BBB}$, they are isoetin; 5,7,8,3',4'-pentamethoxy flavone; and flavenochromane C. 5,7,8,3',4'-pentamethoxy flavone can strongly bind to NF-kB and TNF- $\alpha$, while Flavenochromane C potentially inhibits MAPK14, NF-kB, and TNF- $\alpha$ better than standard drugs. These compounds are firstly reported as neuroprotective agents. They can be further explored and could be used as a backbone molecule to develop a new treatment for neurodegenerative diseases.
\end{abstract}

Keywords: neurodegenerative; neuroprotective; propolis compounds; docking analysis; binding affinity energy.

(c) 2021 by the authors. This article is an open-access article distributed under the terms and conditions of the Creative Commons Attribution (CC BY) license (https://creativecommons.org/licenses/by/4.0/).

\section{Introduction}

Neurodegenerative diseases affect millions of people worldwide. Neurodegenerative disorders such as Alzheimer's disease (AD), stroke, and Parkinson's disease (PD) are major clinical problems in developed countries [1] and are a major economic burden for health care systems [2]. AD is a common cause of dementia and death. According to WHO, dementia is a symptom of decreased memory, thinking, behavior, and the ability to perform daily activities. Loss of intellectual capacity in dementia is not only in memory but also in cognitive and personality. In 2016, WHO noted that 47.5 million people in the world had dementia, and it will increase to 75.6 million people in 2030 and 135.5 million people in 2050. A new case of dementia occurs every 4 seconds. There are 7.7 million new cases of dementia every year. In 
Indonesia, the prevalence of people with dementia reached 606,100 in 2005 . It will increase to $3,042,000$ in 2050 [3].

Neurodegeneration occurs when nerve cells in the brain or peripheral nervous system lose function over time and eventually die. It is caused by an extracellular neurotoxic microenvironment associated with oxidative stress, chronic inflammation, and mitochondrial dysfunction [4]. All three situations have their signaling mechanisms in nerve loss and interact with each other to promote sustained neurodegenerative damage.

There is still no effective treatment for neurodegenerative diseases, especially Alzheimer's disease. However, there are several types of FDA-approved drugs that can reduce the symptoms of Alzheimer's. Donepezil work as an acetylcholinesterase inhibitor (AChE) in Alzheimer's disease, especially for mild to moderate levels. However, donepezil has side effects such as urinary incontinence, nausea, diarrhea, malaise, dizziness, and insomnia [5,6]. Donepezil also can cause gastrointestinal and neurological adverse reactions such as vomiting, speech difficulty, and involuntary tremors $[7,8]$. Currently, the application of natural products in the prevention of neuroinflammation is a relatively new field, and dietary phytochemical supplementation is proving to be a promising nutritional intervention approach due to its neuroprotective properties as an antioxidant and anti-inflammation [9]. Phytocompounds are safer than synthetic drugs and have negligible side effects. Recent studies show the benefits of using polyphenols to treat neurodegenerative diseases [10,11].

Molecular docking is the preliminary study in drug design tools as a combination of computational techniques and biological molecular structure data to predict the interaction between the ligand and its protein target. The potential of computationally predicted molecules and targets against neurodegenerative diseases has been reported [12-16]. In the case of Alzheimer's disease, several target proteins are potentially inhibited by the drug candidate. P38 $\alpha$ mitogen-activated protein kinase (MAPK14) [17], tumor necrosis factor-alpha (TNF- $\alpha$ ) $[18,19]$, interleukin-1 beta (IL-1 ) [20], and nuclear factor-kappa B (NF-KB) [21] are proteins that are directly involved in the neuroinflammatory processes and activation of microglia. Caspase-3 involved in neuronal apoptotic [22], and Acetylcholinesterase (AChE) act as neurotransmitter breakdown catalyst [23].

Propolis (bee glue) is resinous substance bees collect from tree leaf buds and bark, such as poplars and conifers [24]. Propolis contains pharmacologically active constituents such as polyphenols, terpenoids, steroids, and amino acids. Therefore, propolis has a broad spectrum of various biological and pharmacological activities, including anti-inflammatory, antioxidant, and immunomodulatory actions, due to its polyphenolic composition in flavonoids and phenolic acids [25]. Recent studies have shown that propolis contains potential compounds as neuroprotective agents [26-34]. Brazilian propolis, which contains kaempferol, has been reported to have a neuroprotective effect on preventing oxytosis/ferroptosis in HT22 cells [35]. The flavonoid compound of propolis, namely luteolin, has inhibition activity to LPS-induced microglia activation [36]. In vivo studies of Indian propolis have shown that propolis is a potential treatment for Alzheimer's disease by inhibiting $\mathrm{AChE}$ and increasing brain monoamines [37]. Moreover, in hypoxia-treated microglia, propolis significantly inhibited the expression of pro-inflammatory cytokines such as IL-1 $\beta$, TNF- $\alpha$, and IL-6; generation of ROS from mitochondria; and NF-KB activation [29].

Therefore, in this study, we examined the propolis compounds from PT Nano Herbaltama Internasional as a candidate for neuroprotective agents based on their inhibition activity to proteins involved in neurodegenerative through in silico molecular docking. A total of 22 
propolis compounds and four approved drugs were used in this study to dock with six proteins target, namely p38 alpha or MAPK14, caspase 3, NF-KB, IL-1B, TNF alpha, and AChE. Furthermore, molecular interactions between protein targets and propolis compounds were analyzed, and the differencing mechanism in binding ability was also investigated. In addition, absorption, distribution, metabolism, excretion, and toxicity (ADMET) analysis of drug candidates were also carried out by in silico method to evaluate pharmacokinetics, psychochemical properties, and drug-likeness of potential compounds.

\section{Materials and Methods}

\subsection{Materials.}

\subsubsection{Ligand preparation.}

There are 26 ligands retrieved in 3D conformer from PubChem database with SDF formats (http://pubchem.ncbi.nlm.nih.gov). 22 ligands of them were propolis bioactive compounds, and the other 4 were Donepezil, Huperzine A, Fostamatinib, and Amrinone. Table 1 shows 22 propolis bioactive compounds obtained from LC-MS/MS analysis of extract propolis by the same method of propolis screening in the previous report [38], whereas the extract propolis was also supplied from PT Nano Herbaltama Internasional. All ligands were then prepared by molecular interaction geometry using MMFF94 partial forcefield in CHARMM and converted to .pdb format using the Discovery Studio 2020. Ligands, which are not available in PubChem, are generated to 3D structure and optimized molecular geometry using Discovery Studio 2020 then saved in .pdb format.

Table 1. The identified compounds of propolis.

\begin{tabular}{|c|c|c|c|c|}
\hline No & Compound & Pubchem ID & Formula & Structure \\
\hline 1 & Stachydrine & 115244 & $\mathrm{C}_{7} \mathrm{H}_{13} \mathrm{NO}_{2}$ & \\
\hline 2 & $2 \beta, 3 \beta$-Dihydroxy nortopane* & - & $\mathrm{C}_{7} \mathrm{H}_{13} \mathrm{NO}_{2}$ & \\
\hline 3 & 3ß,6exo-Dihydroxy nortopane* & - & $\mathrm{C}_{7} \mathrm{H}_{13} \mathrm{NO}_{2}$ & \\
\hline 4 & Gentiatibetine & 5317559 & $\mathrm{C}_{9} \mathrm{H}_{11} \mathrm{NO}_{2}$ & \\
\hline 5 & 6-Hydroxykaempferol & 5281638 & $\mathrm{C}_{15} \mathrm{H}_{10} \mathrm{O}_{7}$ & \\
\hline 6 & $5,7,8,3^{\prime}, 4^{\prime}$-Pentamethoxy flavone* & - & $\mathrm{C}_{15} \mathrm{H}_{10} \mathrm{O}_{7}$ & \\
\hline 7 & Viscidulin I & 5320471 & $\mathrm{C}_{15} \mathrm{H}_{10} \mathrm{O}_{7}$ & \\
\hline
\end{tabular}




\begin{tabular}{|c|c|c|c|c|}
\hline No & Compound & Pubchem ID & Formula & Structure \\
\hline 8 & Isoetin & 5281649 & $\mathrm{C}_{15} \mathrm{H}_{10} \mathrm{O}_{7}$ & \\
\hline 9 & Morin & 5281670 & $\mathrm{C}_{15} \mathrm{H}_{10} \mathrm{O}_{7}$ & \\
\hline 10 & Herbacetin & 5280544 & $\mathrm{C}_{15} \mathrm{H}_{10} \mathrm{O}_{7}$ & \\
\hline 11 & Quercetin & 5280343 & $\mathrm{C}_{15} \mathrm{H}_{10} \mathrm{O}_{7}$ & \\
\hline 12 & Delphinidin & 68245 & $\mathrm{C}_{15} \mathrm{H}_{10} \mathrm{O}_{7}$ & \\
\hline 13 & Robinetin & 5281692 & $\mathrm{C}_{15} \mathrm{H}_{10} \mathrm{O}_{7}$ & \\
\hline 14 & Fisetin & 5281614 & $\mathrm{C}_{15} \mathrm{H}_{11} \mathrm{ClO}_{7}$ & \\
\hline 15 & $\begin{array}{l}\text { 7-Hydroxy-1-methoxy-2- } \\
\text { methoxyxanthone* }\end{array}$ & - & $\mathrm{C}_{15} \mathrm{H}_{10} \mathrm{O}_{7}$ & \\
\hline 16 & Kaempferol & 5280863 & $\mathrm{C}_{15} \mathrm{H}_{10} \mathrm{O}_{6}$ & \\
\hline 17 & $5,7,8,4^{\prime}$-Tetrahydroxy flavone* & - & $\mathrm{C}_{15} \mathrm{H}_{10} \mathrm{O}_{6}$ & \\
\hline 18 & 3-Hydroxy baicalein* & - & $\mathrm{C}_{15} \mathrm{H}_{10} \mathrm{O}_{6}$ & \\
\hline 19 & Luteolin & 5280445 & $\mathrm{C}_{15} \mathrm{H}_{10} \mathrm{O}_{6}$ & \\
\hline 20 & Flavenochromane $\mathrm{C}$ & 11451469 & $\mathrm{C}_{15} \mathrm{H}_{10} \mathrm{O}_{6}$ & \\
\hline 21 & $\begin{array}{l}\text { 3,4',5-Trihydroxy-7-methoxy-8- } \\
\text { isopentenylflavone* }\end{array}$ & - & $\mathrm{C}_{15} \mathrm{H}_{10} \mathrm{O}_{6}$ & \\
\hline 22 & Icaritin & 5318980 & $\mathrm{C}_{21} \mathrm{H}_{20} \mathrm{O}_{6}$ & \\
\hline
\end{tabular}




\subsubsection{Protein preparation.}

Six proteins were used as the target: MAPK14, Caspase-3, NF-kB, IL-1 $\beta$, TNF-alpha, and AChE. Those protein structures were obtained from Protein Data Bank (PDB) (http://www.rcsb.org/pdb) with their PDB codes in Table 2. Each protein structure was prepared using the Discovery Studio by removing water molecules, ligand molecule, heteroatom, and given polar hydrogen and charges then saved in pdb file. The binding site of each protein was identified by the Computed Atlas of Surface Topography of Protein (CASTp). The binding pocket of each protein was shown in Figure 1, whereas the key residue was presented in Table 1.

\subsubsection{Softwares, hardware, and web server tools.}

AutodockVina, Discovery Studio Visualizer (BIOVIA) 2021, PyRx 0.8, Open Babel v 2.4.1, and Protein Data Bank (PDB), PubChem, Drugbank, CASTp 3.0, SwissADME, ADMETscbdd, and UniProt web server were used in this study with ASUS VivoBook A442U, Intel ${ }^{\circledR}$ Core $^{\mathrm{TM}}$ i5 $8550 \mathrm{U}$, CPU up to $3.40 \mathrm{GHz}, 8 \mathrm{~GB}$ RAM, Microsoft Windows 10 - 64 bit.

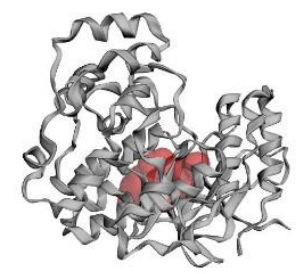

(a)

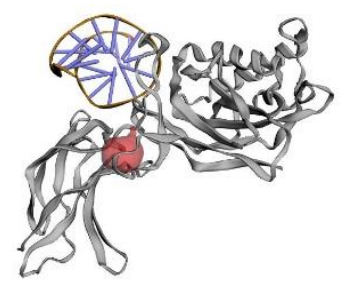

(c)

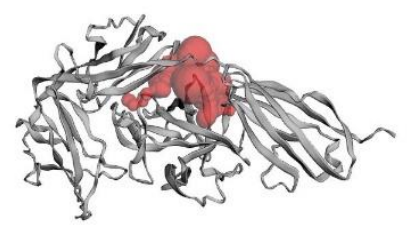

(e)

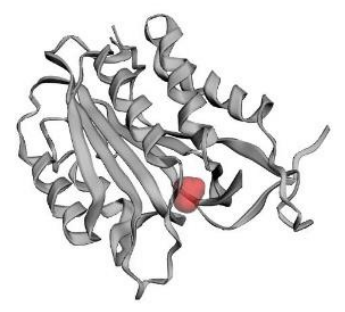

(b)

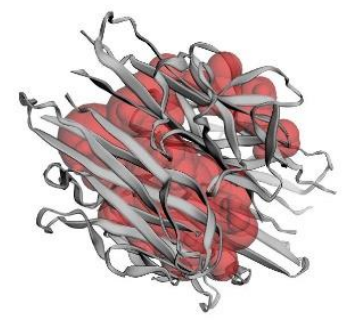

(d)

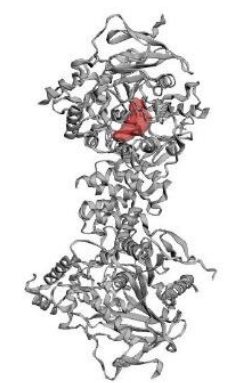

(f)

Figure 1. Protein binding pocket visualization from CASTp: (a) MAPK14; (b) Caspase 3; (c) NFKB; (d) TNF$\alpha ;(\mathbf{e}) \mathrm{IL}-1 \beta ;$ (f) AChE.

Table 2. Grid selection and targeted key residue. 


\begin{tabular}{|c|c|c|c|}
\hline \multirow{2}{*}{$\begin{array}{l}\text { Protein } \\
\text { (PDB } \\
\text { Code) }\end{array}$} & \multirow[t]{2}{*}{ Key Residue } & \multicolumn{2}{|c|}{ Grid selection } \\
\hline & & Center & Dimension \\
\hline $\begin{array}{l}\text { MAPK1 } \\
4 \\
(3 \mathrm{U} 8 \mathrm{~W})\end{array}$ & $\begin{array}{l}\text { Val30, Ser32, Gly33, Ala34, Val38, Ala51, Lys53, Glu71, Leu74, } \\
\text { Leu75, Ile84, Leu104, Thr106, His107, Leu108, Met109, Gly110, } \\
\text { Ala111, Asp112, Asn115, Ser154, Asn155, Ala157, Leu167, Asp168, } \\
\text { Phe169 }\end{array}$ & $\begin{aligned} X & : 1.0244 \\
Y & :-28.8636 \\
Z & :-29.6576\end{aligned}$ & $\begin{array}{l}X: 28.2443 \\
Y: 25.947 \\
Z: 23.0276\end{array}$ \\
\hline $\begin{array}{l}\text { Caspase } \\
3 \\
(1 \mathrm{PAU})\end{array}$ & $\begin{array}{l}\text { Arg179, Ser236, His237, Gln283, Ala284, Cys285 (Chain A), Ser339, } \\
\text { Arg341 (Chain B), Val504 (Chain C) }\end{array}$ & $\begin{array}{l}X: 33.5214 \\
Y: 96 \\
Z: 18.7904\end{array}$ & $\begin{array}{l}X: 15.3976 \\
Y: 14.0208 \\
Z: 16.2711\end{array}$ \\
\hline $\begin{array}{l}\text { NFKB } \\
(1 \mathrm{SVC})\end{array}$ & $\begin{array}{l}\text { Lys52, Arg54, Gly55, Ser243, Ala248, Ser249, Asn250, Leu251, } \\
\text { Arg336, Glu341, Thr342, Ser343, Glu344 }\end{array}$ & $\begin{array}{l}X: 33.031 \\
Y: 11.2666 \\
Z: 36.6877\end{array}$ & $\begin{array}{l}X: 18.1556 \\
Y: 20.1816 \\
Z: 19.6488\end{array}$ \\
\hline $\begin{array}{l}\text { TNF- } \alpha \\
(2 \mathrm{AZ5})\end{array}$ & $\begin{array}{l}\text { Asp10, Lys11, Pro12, Val13, Ala14, His15, Val17, Leu36, Ala38, } \\
\text { Asn39, Leu55, Leu57, Ile58, Tyr59, Ser60, Gln61, Leu63, Phe64, } \\
\text { Lys98, Tyr115, Glu116, Pro117, Tyr119, Leu120, Gly121, Gly122, } \\
\text { Asp143, Glu146, Gly148, Gln149, Tyr151, Ile155, Ala156, Leu157 } \\
\text { (Chain A) Asp10, Lys11, Val13, Asn39, Glu53, Leu55, Leu57, Tyr59, } \\
\text { Ser60, Gln61, Arg82, Ala84, Tyr87, Thr89, Val91, Asn92, Leu93, } \\
\text { Leu94, Ser95, Ala96, Ile97, Lys98, Pro117, Ile118, Tyr119, Leu120, } \\
\text { Gly121, Gly122, Val123, Phe124, Gln125, Leu126, Glu127, Tyr151, } \\
\text { Ile155, Ala156, Leu157 (Chain B) Asp10, Lys11, Pro12, Val13, Ala14, } \\
\text { His15, Val17, Leu36, Asn39, Leu57, Ile58, Tyr59, Ser60, Gln61, } \\
\text { Tyr119, Leu120, Gly121, Gly122, Glu146, Ser147, Gly148, Gln149, } \\
\text { Tyr151, Ile155, Ala156, Leu157 (Chain C) Asp10, Lys11, Glu53, } \\
\text { Gly54, Leu55, Leu57, Tyr59, Ser60, Gln61, Arg82, Ala84, Tyr87, } \\
\text { Thr89, Val91, Asn92, Leu93, Leu94, Ser95, Ala96, Ile97, Tyr119, } \\
\text { Leu120, Gly121, Gly122, Val123, Phe124, Gln125, Leu126, Glu127, } \\
\text { Tyr151,Ile155, Ala156, Leu157 (Chain D) }\end{array}$ & $\begin{array}{l}\mathrm{X}:-13.1232 \\
\mathrm{Y}: 72.7981 \\
\mathrm{Z}: 26.84\end{array}$ & $\begin{array}{l}X: 50.6851 \\
Y: 53.8103 \\
Z: 35.5497\end{array}$ \\
\hline $\begin{array}{l}\text { IL-1 } \beta \\
(1 \mathrm{ITB})\end{array}$ & $\begin{array}{l}\text { Leu6, Asn7, Arg11, Asp12, Ser13, Gln15, Ser17, His30, Leu31, } \\
\text { Met36, Met44, Phe46, Ile56, Lys103, Glu105, Ile106, Asn107, } \\
\text { Asn108, Lys109, Leu110, Thr147, Met148, Gln149, Phe150, Val151, } \\
\text { Ser152 (Chain A) Phe111, Lys112, Gln113, Lys114, Leu115, Pro116, } \\
\text { Val117, Ala118, Gly119, Asp120, Gly121, Gly122, Arg163, Leu201, } \\
\text { Glu202, Glu203, Asn204, Lys205, Pro206, Thr207, Gln236, Leu237, } \\
\text { Ser238, Asp239, Ile240, Glu265, Lys270, Arg271, Lys298, Asn299, } \\
\text { Thr300, His301 (Chain B ) }\end{array}$ & $\begin{array}{l}X: 40.4042 \\
Y: 13.6582 \\
Z: 17.7521\end{array}$ & $\begin{array}{l}X: 38.1724 \\
Y: 30.6079 \\
Z: 30.6678\end{array}$ \\
\hline $\begin{array}{l}\text { AChE } \\
\text { (4EY7) }\end{array}$ & $\begin{array}{l}\text { Gln71, Tyr72, Asp74, Thr83, Trp86, Asn87, Pro88, Gly120, Gly121, } \\
\text { Gly122, Tyr124, Ser125, Gly126, Leu130, Tyr133, Glu202, Ser203, } \\
\text { Ala204, Trp236, Trp286, Leu289, Ser293, Val294, Phe295, Arg296, } \\
\text { Phe297, Tyr337, Phe338, Tyr341, His447, Gly448, Ile451 }\end{array}$ & $\begin{array}{l}X:-11.5323 \\
Y:-42.8618 \\
Z: 29.0781\end{array}$ & $\begin{array}{l}X: 25.9876 \\
Y: 21.9535 \\
Z: 31.9628\end{array}$ \\
\hline
\end{tabular}

\subsection{Methods.}

\subsubsection{Molecular docking and visualization.}

The molecular docking of ligand and protein molecules was carried out using the Autodock Vina-based Pyrx 0.8 program. Docking for all ligands was performed in the sitespecific docking by the grid selection parameters (Table 2), then the rest of the setting was left at default. The docking result shows each ligand's binding affinity with the optimum conformation and best model at the protein's binding site. This binding result table and the best model for each protein-ligand interaction were saved from being visualized. Docking visualization was done using Discovery Studio 2020 (BIOVIA) for 3D conformation and 2D binding interaction.

\subsubsection{ADMET analysis.}

Adsorption, distribution, metabolism, and excretion analysis was performed by entering the SMILES of each ligand to the SwissADME web server (http://www.swissadme.ch/), while the toxicity analysis was done by ADMETlab (http://admet.scbdd.com/) web-server. Each ligand's SMILES (Simplified Molecular Input Line Entry System) were obtained from Pubchem (https://pubchem.ncbi.nlm.nih.gov/). However, ligands that were not available in 
PubChem, their SMILES were obtained from converted smi.file from sdf file of the compound by Discovery studio. All the ligand's SMILES were collected to be a single .sdf file using Open Babel v.2.4.1 software. This single sdf.file of all ligands was used to analyze the LD50 acute toxicity prediction in ADMETlab. Some properties of ADMET used in the present study are shown in Table 3. with the acceptable values as follow [39]:

Table 3. ADMET parameters.

\begin{tabular}{c|c|c} 
No & Properties & Acceptable values \\
\hline 1 & Molecular weight (MW) & $150-500 \mathrm{~g} / \mathrm{mol}$ \\
\hline 2 & Molecular Refractory (MR) & $40-130$ \\
\hline 3 & Topological Polar surface Area (TPSA) & $20-140 \AA$ \\
\hline 4 & Lipopilicity (XLOGP3) & $-0.7 \pm 6.0$ \\
\hline 5 & Estimated Solubility (ESOL Log S) & $\leq 6$ \\
\hline 6 & Gastrointestinal Absorption (GI) absorption & High \\
\hline 7 & Lipinski rules & 0, max 1 \\
\hline 8 & Bioavailability Score & 0.55 \\
\hline 9 & Blood Brain Barrire (BBB) & Category 1
\end{tabular}

\section{Results}

\subsection{Molecular docking.}

Molecular docking of 22 propolis compounds and 4 drugs as a positive control was done against six protein targets.

Table 4. Molecular Docking Result.

\begin{tabular}{|c|c|c|c|c|c|c|c|}
\hline \multirow[t]{2}{*}{ No } & \multirow[t]{2}{*}{ Control/ligand } & \multicolumn{6}{|c|}{ Protein } \\
\hline & & AChE & MAPK14 & Casp3 & NF-kB & TNF- $\alpha$ & 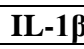 \\
\hline 1 & Donepezil* & -11.7 & - & - & -6.2 & - & -9 \\
\hline 2 & Huperzine A* & - & - & -6.2 & - & - & - \\
\hline 3 & Fostamatinib* & - & -8.4 & - & - & - & - \\
\hline 4 & Amrinone* & - & - & - & - & -6.8 & - \\
\hline 5 & Isoetin & -11.8 & -8.6 & -7.2 & -7.5 & -9.1 & -8.2 \\
\hline 6 & Flavenochromane C & -9.8 & -8.7 & -6.1 & -6.2 & -8.2 & -9.1 \\
\hline 7 & Morin & -10.4 & -8.8 & -6.6 & -6.4 & -7.8 & -7.7 \\
\hline 8 & Icaritin & -9.9 & -8.9 & -6.2 & -6 & -7.9 & -8.9 \\
\hline 9 & $\begin{array}{l}\text { Luteolin } \\
\end{array}$ & -9.8 & -8.6 & -5.7 & -6.4 & -8.9 & -8 \\
\hline 10 & $\begin{array}{l}\text { 3,4',5-Trihydroxy-7-methoxy-8- } \\
\text { isopentenyl flavone }\end{array}$ & -9.7 & -9.2 & -5.6 & -5.6 & -8.1 & -8.5 \\
\hline 11 & Robinetin & -9.7 & -8.9 & -5.7 & -6.1 & -8.8 & -8.1 \\
\hline 12 & $5,7,8,3^{\prime}, 4^{\prime}$-Pentamethoxy flavone & -9.9 & -8.3 & -5.8 & -6.4 & -8.7 & -8.3 \\
\hline 13 & $5,7,8,4^{\prime}$-Tetrahydroxy flavone & -9.8 & -8.3 & -5.9 & -6.2 & -8.3 & -8.1 \\
\hline 14 & Herbacetin & -9.8 & -8.5 & -5.8 & -6.2 & -7.9 & -8.1 \\
\hline 15 & 3-Hydroxy baicalein & -10.4 & -8.6 & -5.6 & -6.2 & -8 & -8.4 \\
\hline 16 & 6-Hydroxy Kaempferol & -9.7 & -8.5 & -5.4 & -6.1 & -8.3 & -8.1 \\
\hline 17 & Fisetin & -9.6 & -8.8 & -5.9 & -5.8 & -8.6 & -7.9 \\
\hline 18 & Quercetin & -9.5 & -8.7 & -5.6 & -6.2 & -8.8 & -8.3 \\
\hline 19 & Delphinidin & -9.5 & -8.3 & -5.4 & -6 & -8.8 & -7.8 \\
\hline 20 & $\begin{array}{l}\text { 7-Hydroxy-1-methoxy-2- } \\
\text { methoxyxanthone }\end{array}$ & -9.5 & -7.9 & -5.9 & -6.4 & -8.2 & -7.6 \\
\hline 21 & Kaempferol & -9.4 & -8.6 & -5.5 & -5.9 & -7.9 & -8.1 \\
\hline 22 & Viscidulin I & -9.2 & -8.3 & -6 & -6.1 & -7.4 & -8.4 \\
\hline 23 & Gentiatibetine & -6.9 & -6.4 & -4.7 & -4.7 & -5.7 & -5.8 \\
\hline 24 & $2 \beta, 3 \beta$-Dihydroxy nortropane & -5.8 & -5.1 & -4.6 & -4.7 & -5.4 & -5.2 \\
\hline 25 & $3 \beta, 6$ exo-Dihydroxy nortropane & -5.8 & -5 & -4.3 & -4.2 & -5.2 & -5.5 \\
\hline 26 & Stachydrine & -5.3 & -4.6 & -4 & -3.7 & -4.9 & -4.7 \\
\hline
\end{tabular}

*positive control for each protein target; Red colors are marked as binding affinity threshold for each proteome and bold-blue marked binding affinity passing the threshold, thus stating the potential ligands 
The docking result displays each protein-ligand interaction's binding affinity $(\Delta \mathrm{G})$ in $\mathrm{kcal} / \mathrm{mol}$ unit. Potential compounds were selected based on propolis ligan's more negative binding affinity than drugs (positive control) to each protein target.

The docking result shows that 18 of 22 propolis compounds have a lower binding affinity than the positive control. These potential compounds of propolis can act to multiple targets in neurodegenerative. Luteolin, herbacetin, 3-hydroxy baicalein, quercetin, and 7hydroxy-1-methoxy-2-methoxyxanthone can be able to bind with three protein targets, namely MAPK14, NF-kB, and TNF- $\alpha$. Meanwhile, icaritin potentially bind to caspase3, NF-KB, and TNF- $\alpha$. There are top three ligands of propolis that have good inhibition to protein targets namely, isoetin, flavenochromane $\mathrm{C}$, and morin. Flavenochromone $\mathrm{C}$ potentially binds to MAPK14, NF-kB, TNF- $\alpha$, and IL-1 $\beta$. While morin binds to Caspase 3 , NF-kB, TNF- $\alpha$, and IL-1 $\beta$. Overall, isoetin has lowest binding energy neurodegenerative-related proteins such as AChE $(11.7 \mathrm{kcal} / \mathrm{mol})$, TNF-alpha $(-9,1 \mathrm{kcal} / \mathrm{mol})$, caspase $3(-7.2 \mathrm{kcal} / \mathrm{mol})$, and NF-kB $(-7,5$ $\mathrm{kcal} / \mathrm{mol})$.

\subsection{Molecular interaction.}

In this section, the molecular interaction of the selected ligand-protein complex will be displayed.

3.2.1. AChE.

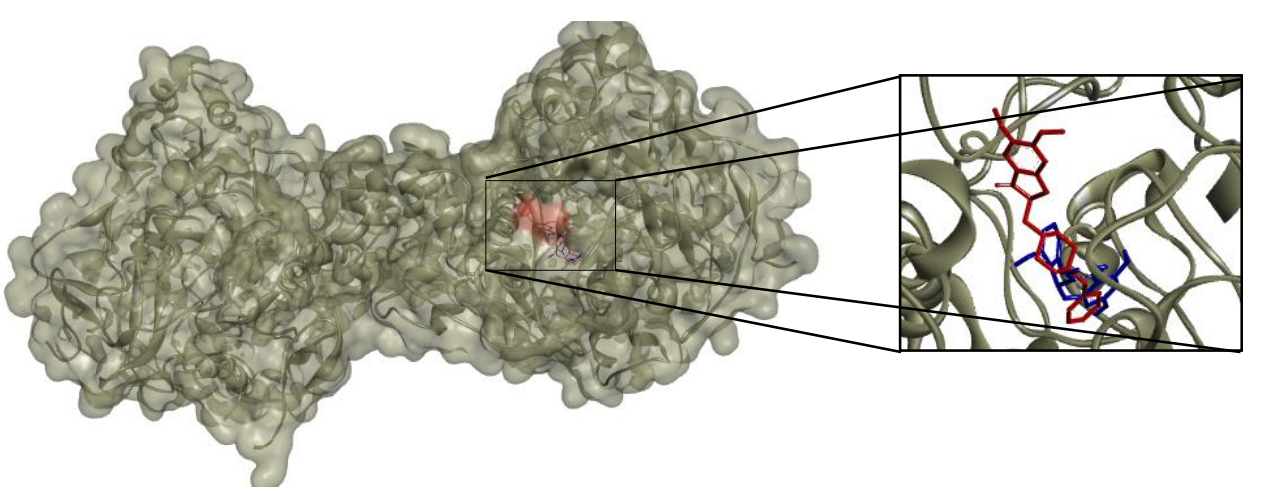

Figure 2. Binding orientation of donepezil (red color) and isoetin (blue color) with AChE.

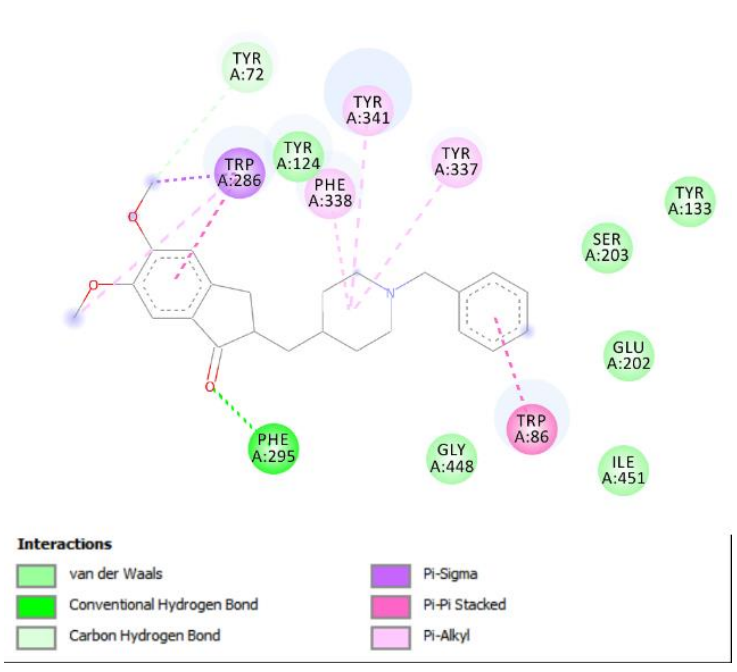

(a)

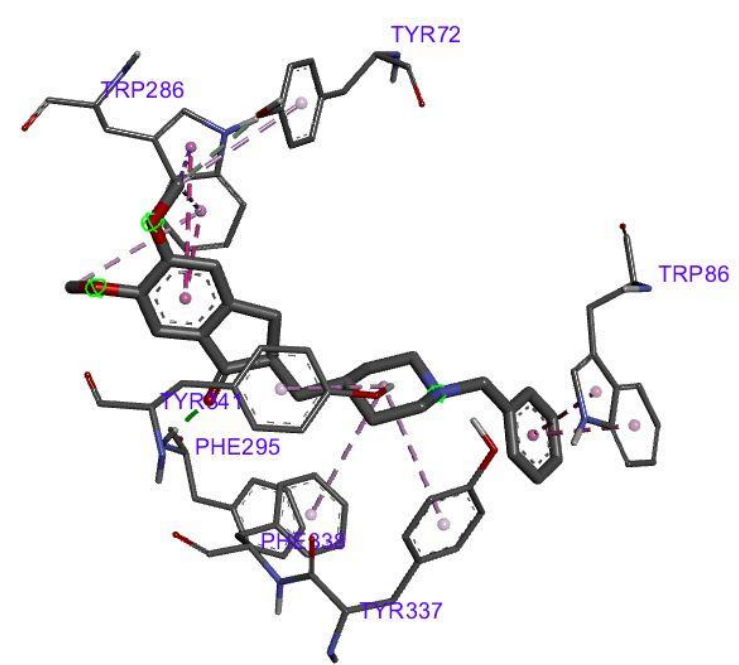

(b)

Figure 3. Molecular interaction between AChE and donepezil. 


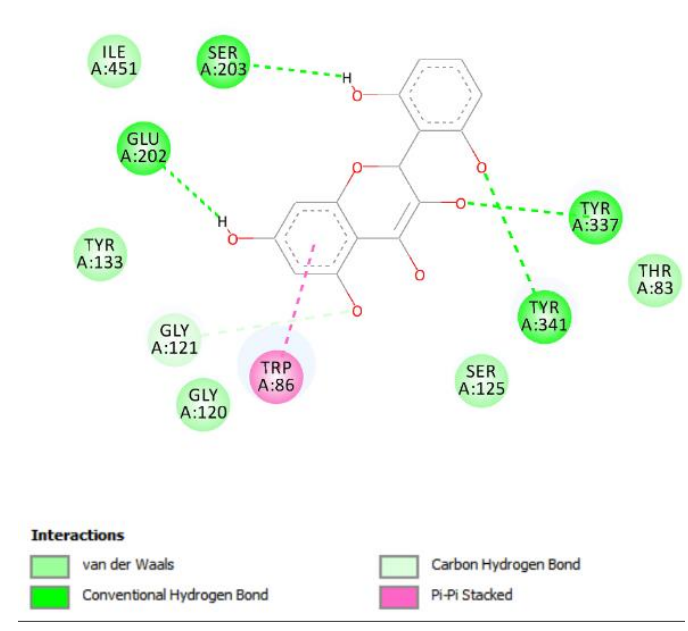

(a)

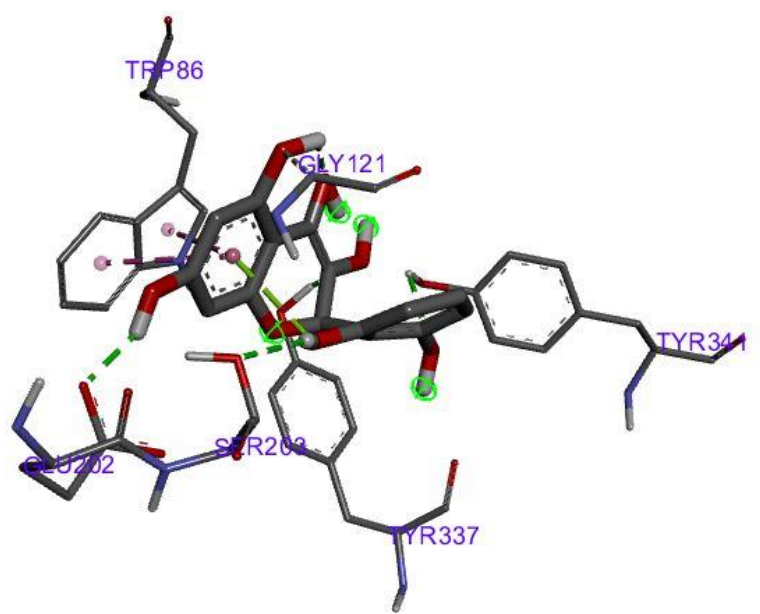

(b)

Figure 4. Molecular interaction between $\mathrm{AChE}$ and (a) Isoetin 2D; (b) Isoetin 3D.

Molecular interaction of donepezil with AChE forms hydrogen bonds with Phe A:295, carbon-hydrogen bonds with Tyr72, pi-Sigma with Trp286, and pi-alkyl with Tyr337, Phe338, Tyr341. Donepezil shared the same amino acid residue (Trp86) as isotein with the same interaction of pi-pi stacked. Isoetin forms hydrogen bonds with Glu202, Ser203, Tyr341, Tyr337, Carbon-Hydrogen Bonds with Gly A:121, and Pi-Pi Stacked with Trp A:86.

\subsubsection{Caspase 3.}

Based on Figure 5, there are four bonding forms at the binding site interaction of isoetin with caspase3, whereas Arg341 formed hydrogen bond, pi-cation, and pi-sulfur interaction as well as Cys285 form pi-sulfur interaction. Morin forms hydrogen bonds with Arg341 and Ser178, carbon-hydrogen bonds with His237,pi-pi stacked with Tyr338, and van der Waal interaction with Cys A285 (Fig. 5c). The same amino acid, Arg 341 also observed to form a hydrogen bond in the binding site of huperzin A to caspase 3.

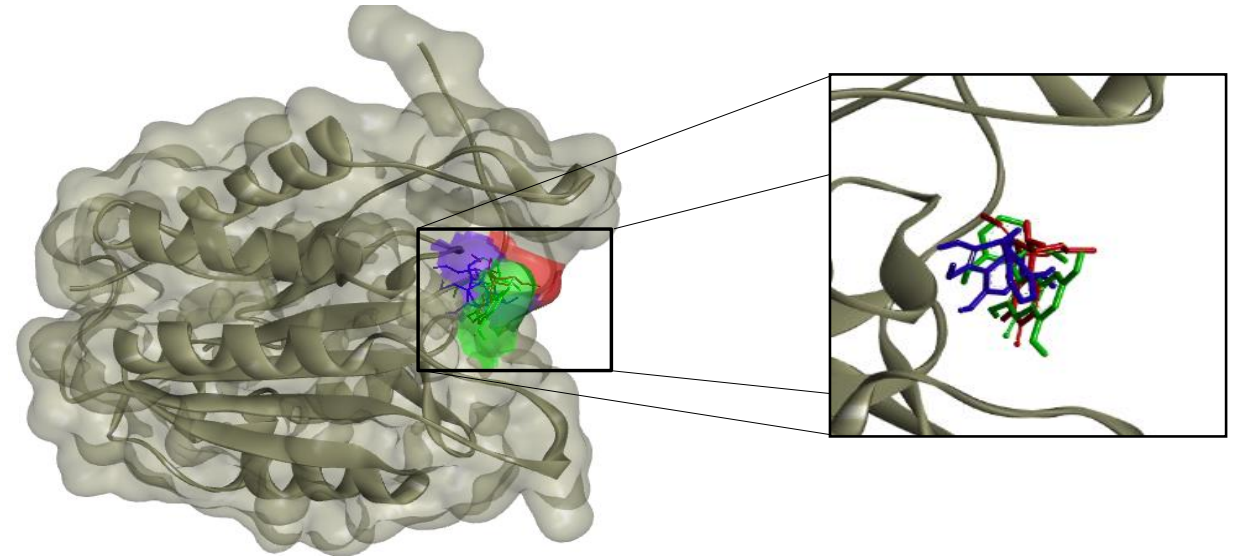

Figure 5. Binding orientation of donepezil(red color), isoetin (blue color), and morin (green color) with Caspase-3.

\subsubsection{MAPK14.}

On the interaction of MAPK14 with 3,4',5-trihydroxy-7-methoxy-8-isopentenyl flavone, there are five hydrogen bonds formed at the binding site with the ligand. 


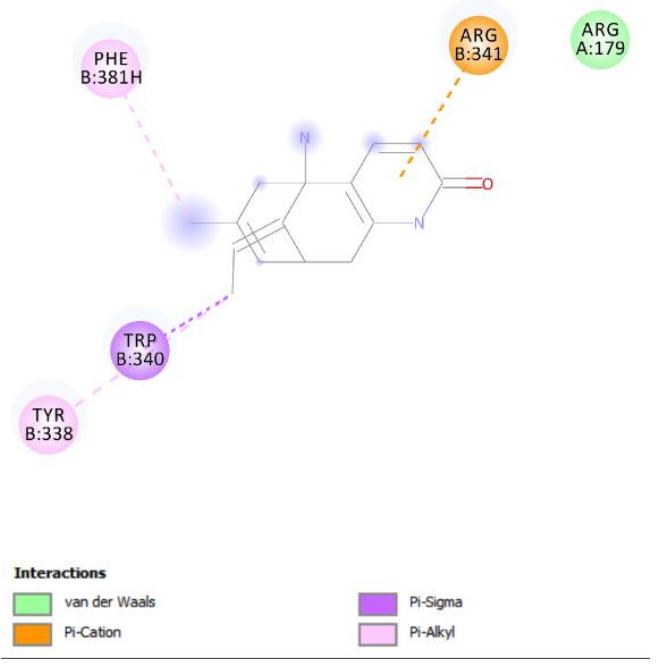

(a)

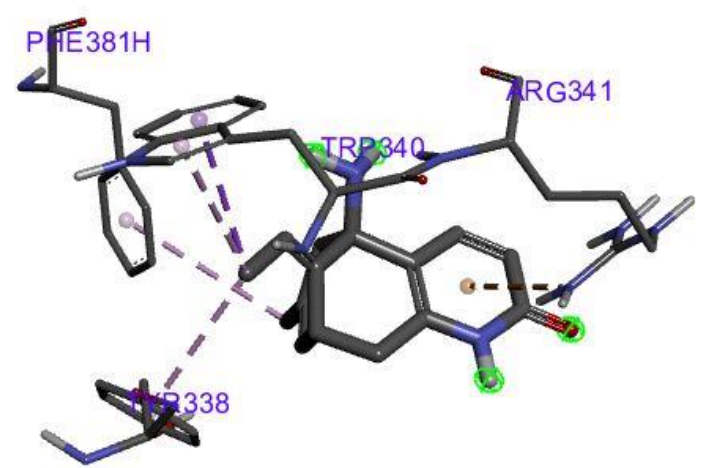

Figure 6. Molecular interaction between Caspase 3 and Huperzine A (a) 2D; (b) 3D.
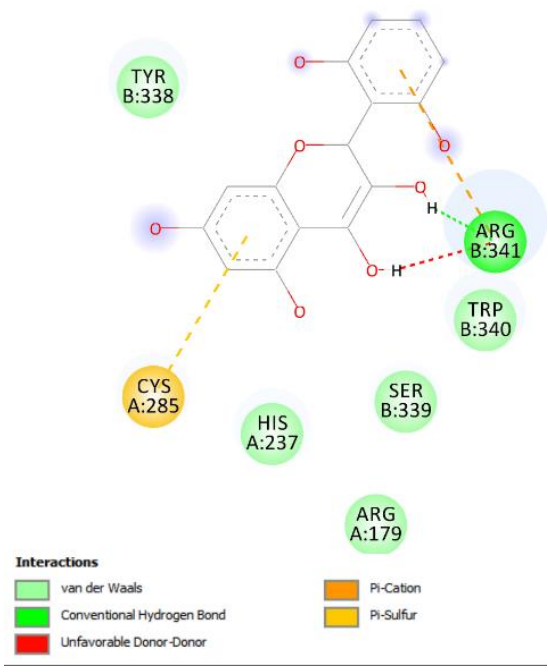

(a)

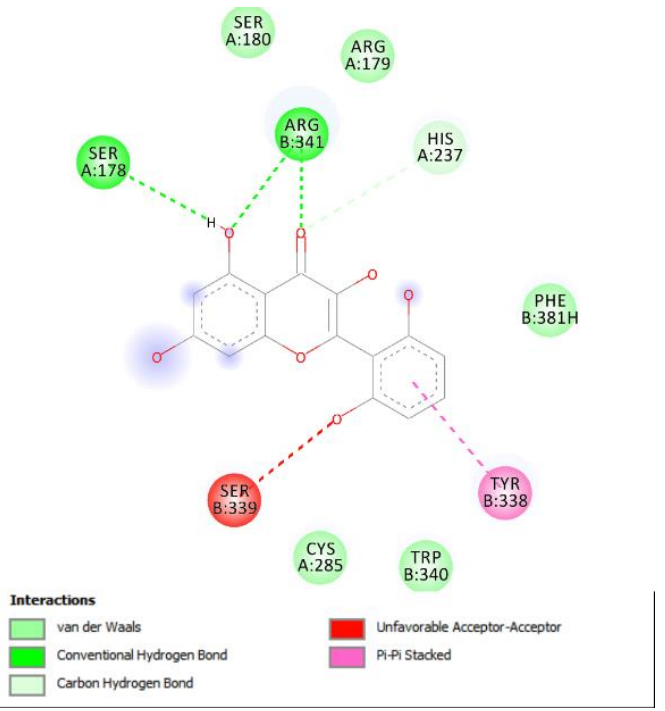

(c)

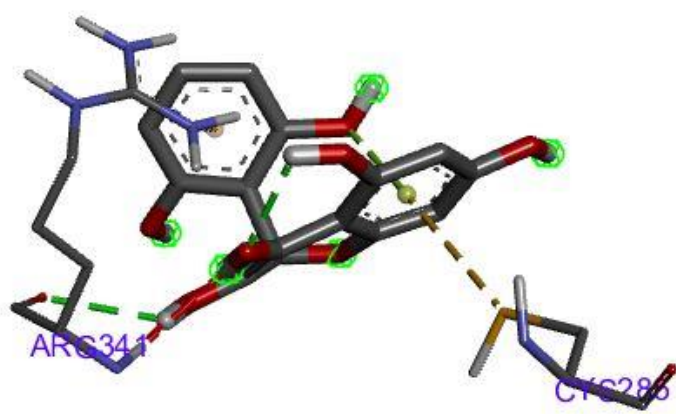

(b)

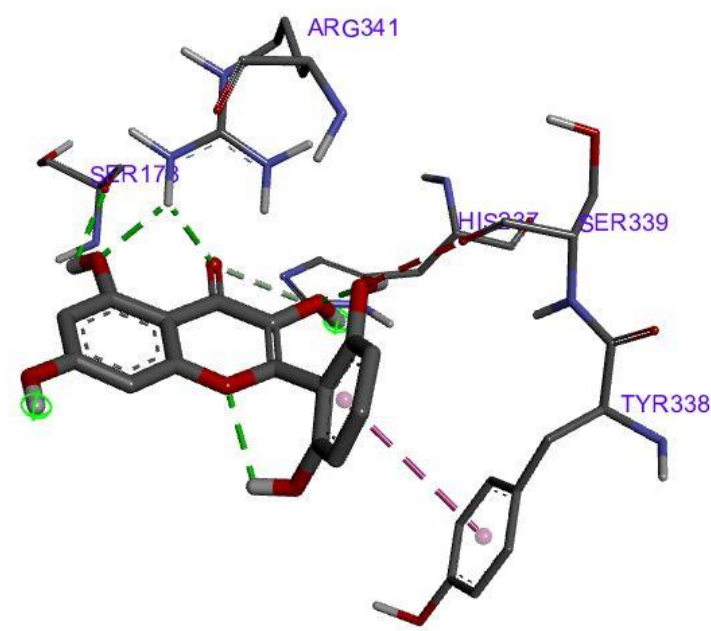

(d)

Figure 7. Molecular interaction between Caspase 3 and (a) Isoetin 2D; (b) Isoetin 3D; (c) Morin 2D; (d) Morin 3D. 


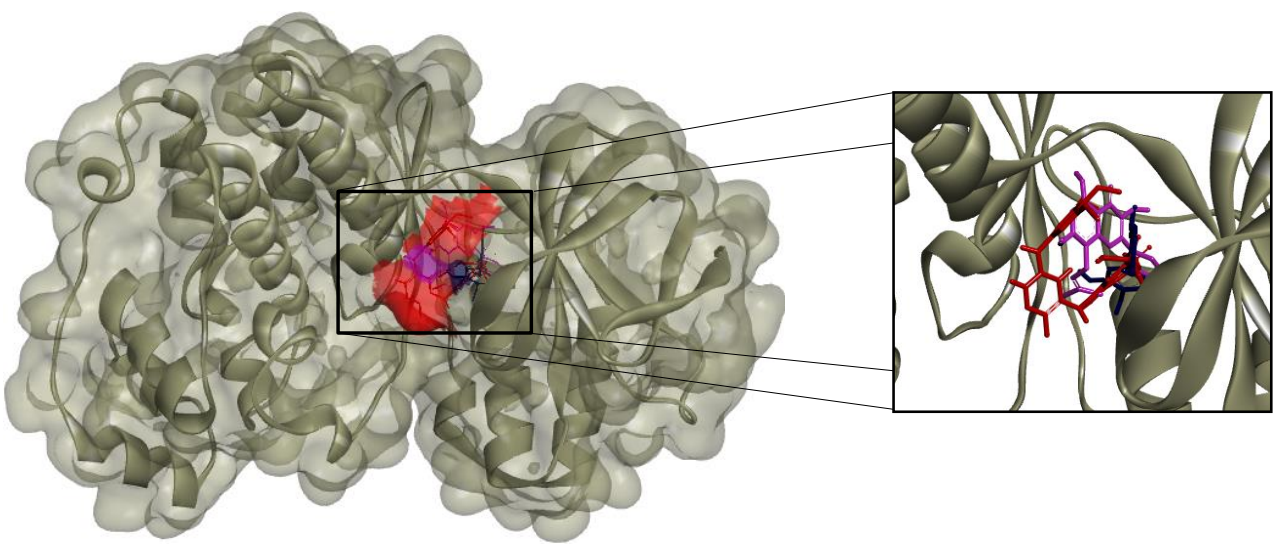

Figure 8. Binding orientation of fostamatinib(red color), 3,4',5-Trihydroxy-7-methoxy-8-isopentenyl flavone (purple color), and robinetin (dark blue color) with MAPK14.

They are Glu71, Thr106, His107, Met109, Ala111, while carbon-hydrogen bonds formed with Asp112, pi-sigma formed with Leu167, Alkyl formed with Ala51, Ile84, Ala157, and pi-alkyl formed with Ala51, Ile84, Ala157.

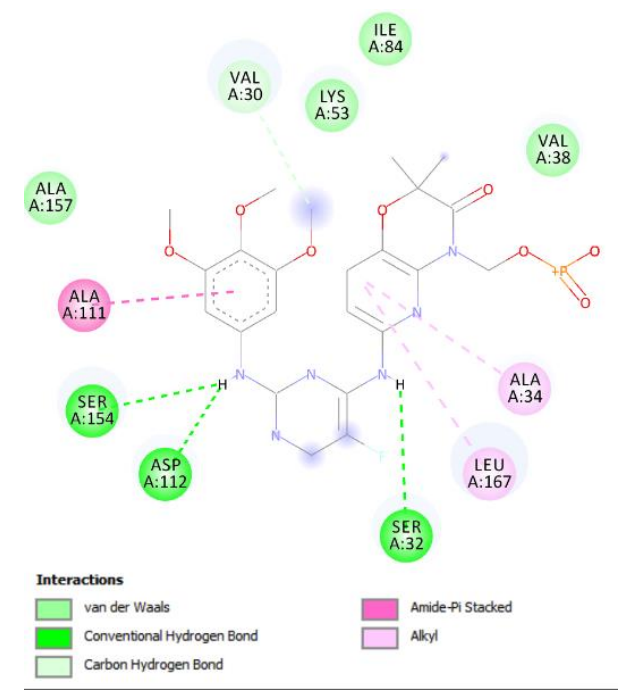

(a)

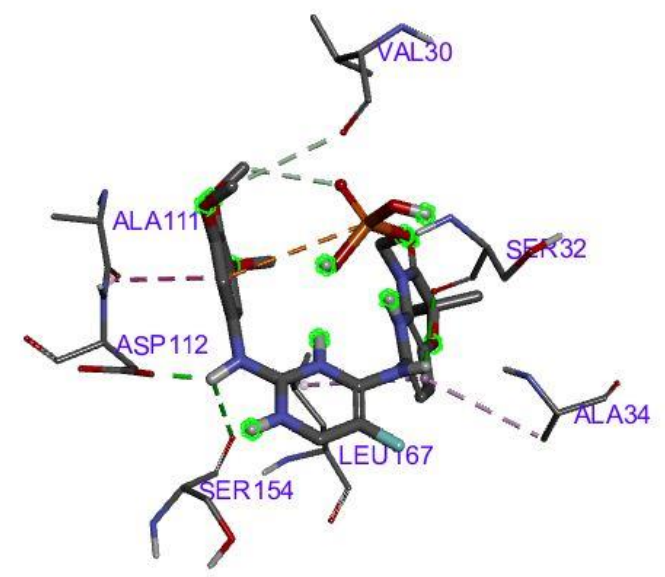

(b)

Figure 9. Molecular interaction between MAPK14 and Fostamatinib: (a) 2D; (b) 3D.

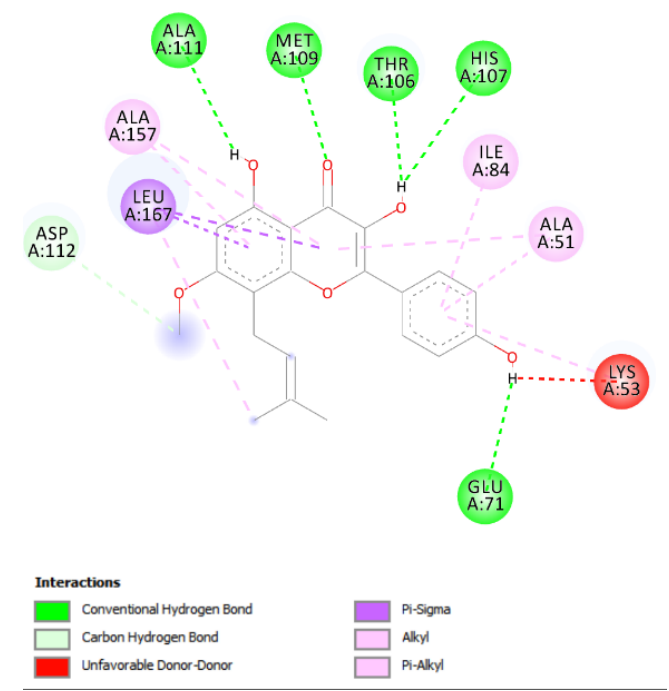

(a)

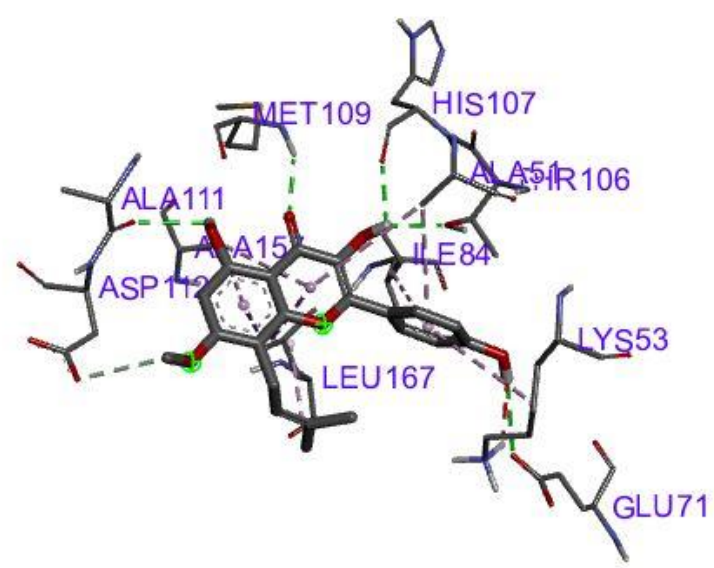




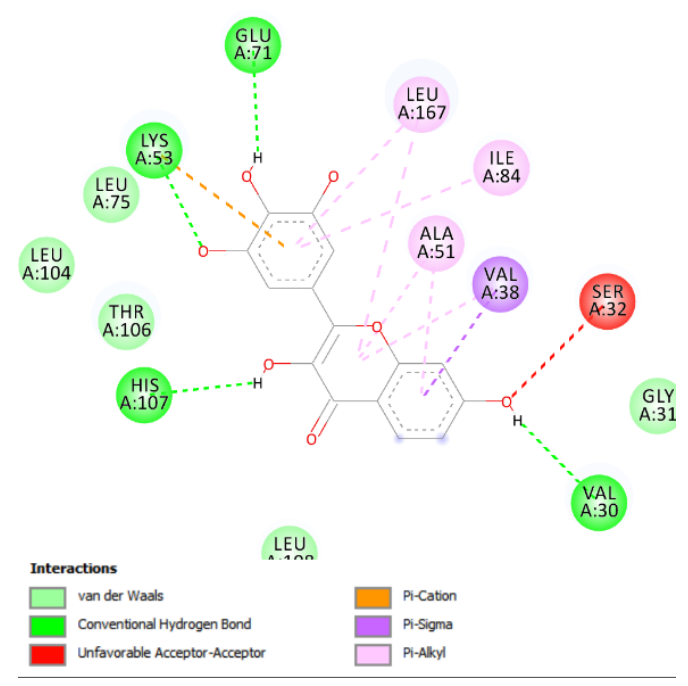

(c)

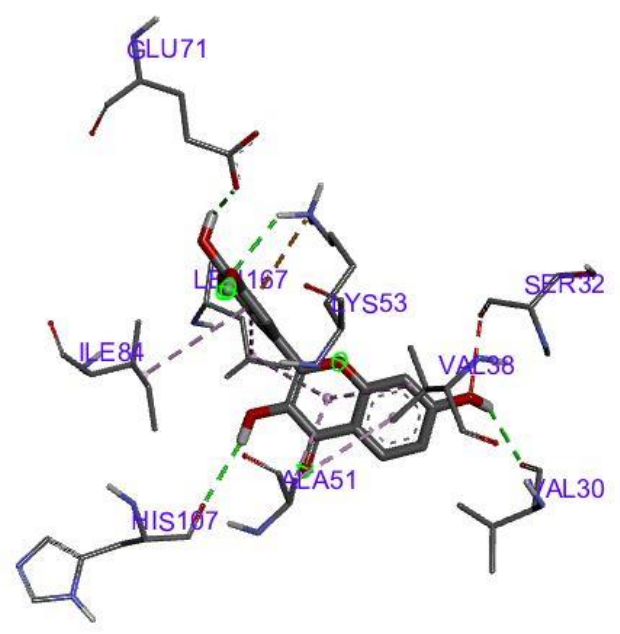

(d)

Figure 10. Molecular interaction between MAPK14 and (a) 3,4',5-Trihydroxy-7-methoxy-8-isopentenyl flavone 2D; (b) 3,4',5-Trihydroxy-7-methoxy-8-isopentenyl flavone 3D; (c) Robinetin 2D; (d) Robinetin 3D.

Leu167 was also observed in the interaction of robinetin to MAPK14. Robinetin formed four hydrogen bonds at MAPK14 binding site, are Val30, Lys53, Glu71, His107, while pication formed with Lys53, pi-sigma formed with Val38, pi-alkyl formed with Ala51, Ile84, Leu167, and van der Waals formed with Gly31, Leu75, Leu104, Thr106, Leu108. Ala111, Leu167, and Asp112 were also found in the interaction of fostamatinib to MAPK14 with different bonding forms.

\subsubsection{NF-KB.}

Molecular interaction of isoetin and NF-kB form two hydrogen bonds with Lys52 and Arg54, pi-anion interaction with Glu341, pi-alkyl interaction with Arg54. Furthermore, 5,7,8,3', $4^{\prime}$-pentamethoxy flavone formed hydrogen bonds with Asn250, pi-anion interaction with Glu341, pi-alkyl interaction with Lys52. Lys52 was observed in all ligand interactions to NF-kB's binding site, including donepezil with NF-kB as standard.

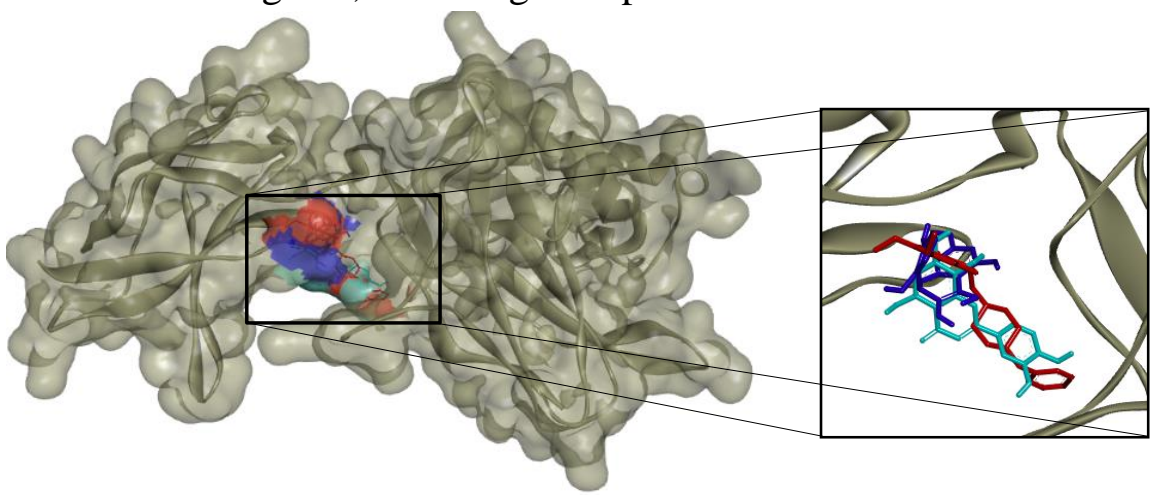

Figure 11. Binding orientation of donepezil (red color), isoetin (blue color), and 5,7,8,3',4'-Pentamethoxy flavone (Tosca color) with NF-kB. 


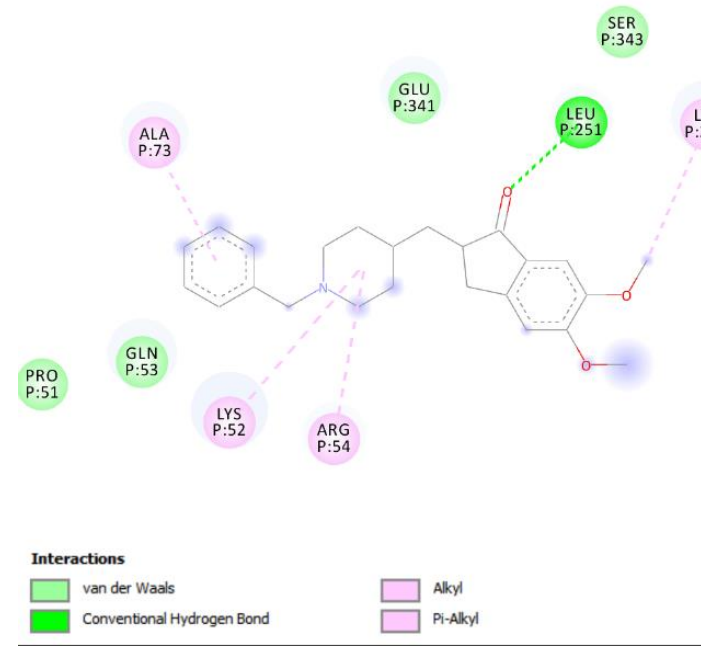

(a)

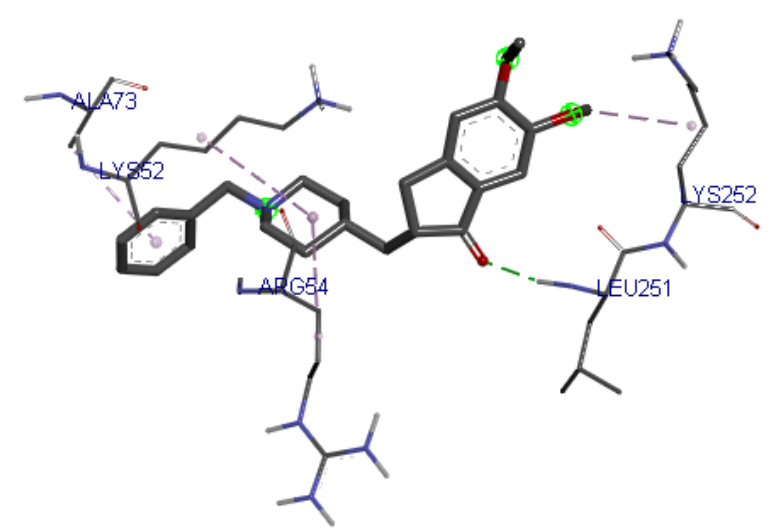

(b)

Figure 12. Molecular interaction between NFKB and Donepezil (a) 2D (b) 3D.

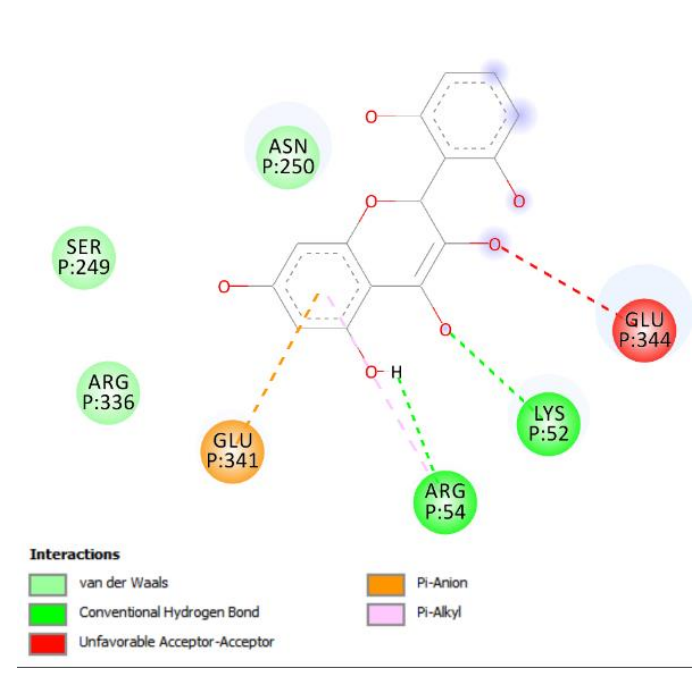

(a)

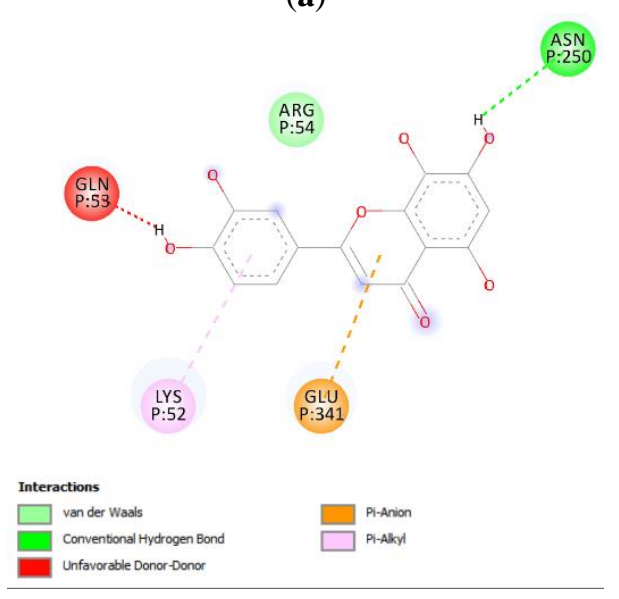

(c)

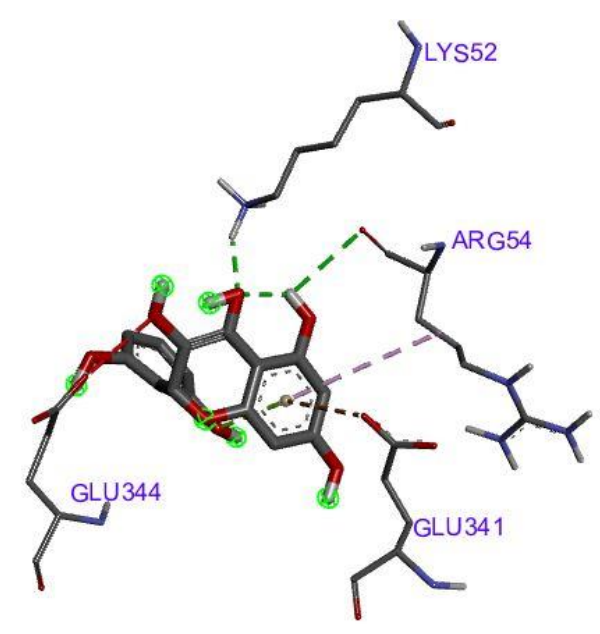

(b)

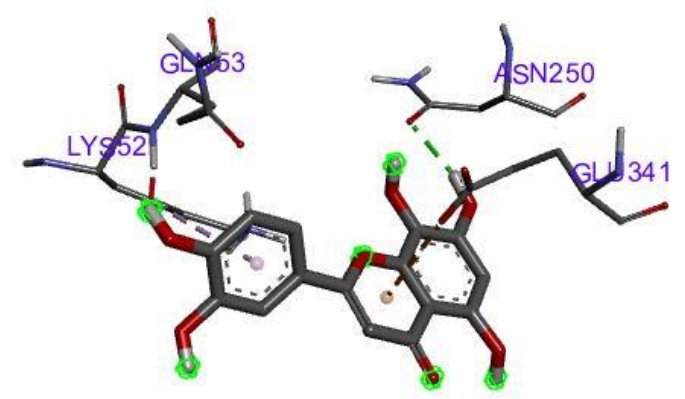

Figure 13. Molecular interaction between NFKB and (a) Isoetin 2D; (b) Isoetin 3D; (c) 5,7,8,3', $4^{\prime}$ Pentamethoxy flavone 2D; (d) 5,7,8,3',4'-Pentamethoxy flavone 3D.

\subsubsection{TNF- $\alpha$.}

Molecular interaction of isoetin and TNF- $\alpha$ form a pi-donor hydrogen bond and pi-pi T-shaped interaction with Tyr D:59, also pi-alkyl interaction with Leu C:57and Leu D:57. 
While, luteolin forms hydrogen bonds with Leu B:93, Leu D:93, also pi-alkyl interaction with Val B:91 and Val D:91. Leu B:93 and Leu D:93 also observed in the molecular interaction of amrinone with TNF- $\alpha$ as standard. Although isoetin binds to a different binding pocket of TNF$\alpha$ with amrinone and luteolin, Isoetin has the lowest binding affinity to TNF- $\alpha$.

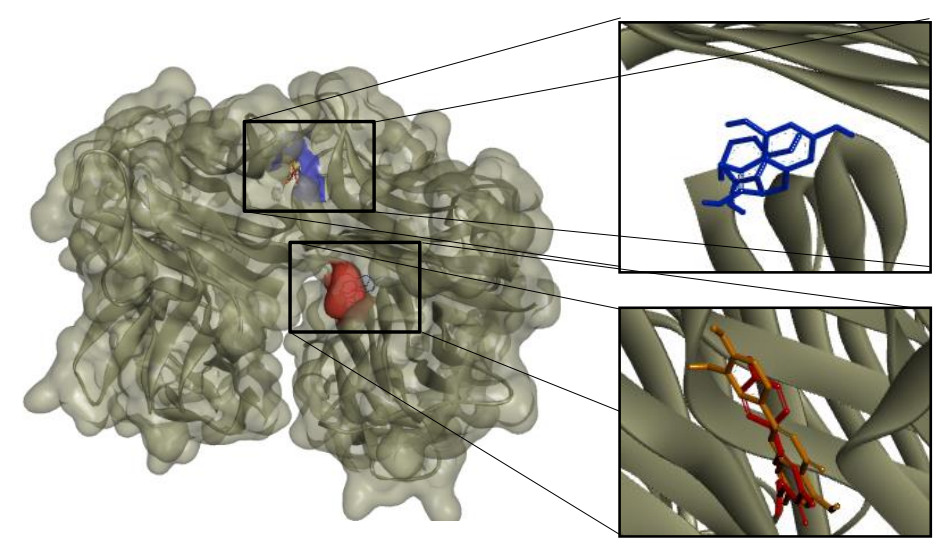

Figure 14. Binding orientation of amrinone (red colour) Isoetin (blue colour) and luteolin (orange colour) with TNF- $\alpha$.

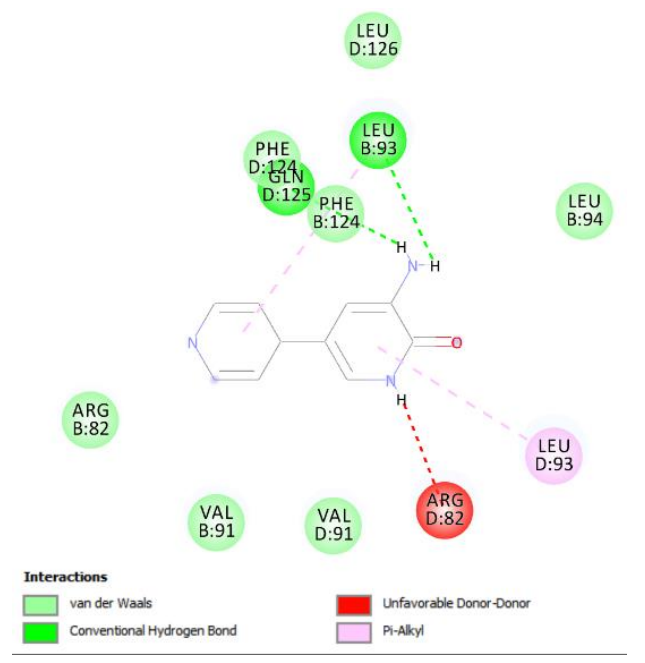

(a)

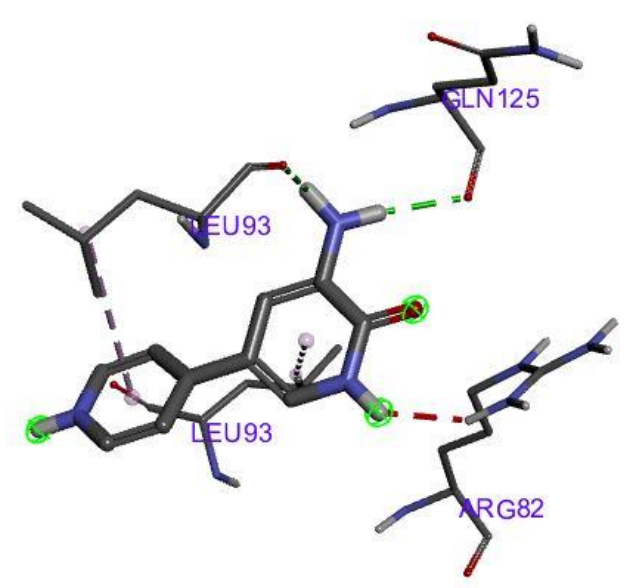

(b)

Figure 15. Molecular interaction between TNF- $\alpha$ with Amrinone (a) 2D; (b) 3D.

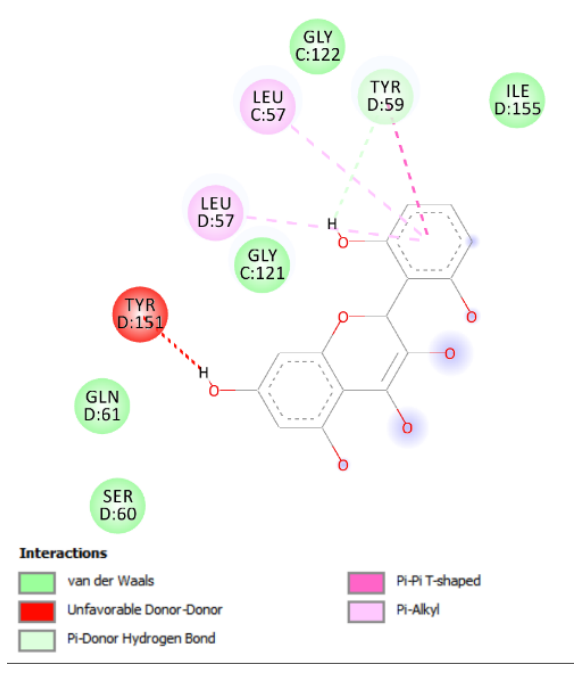

(a)

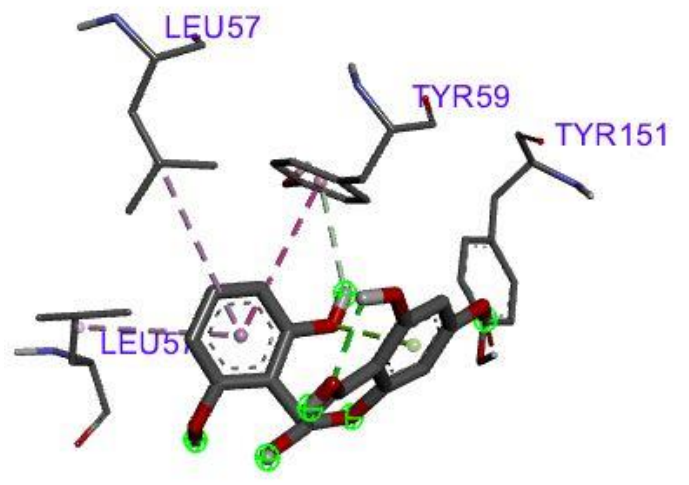

(b) 


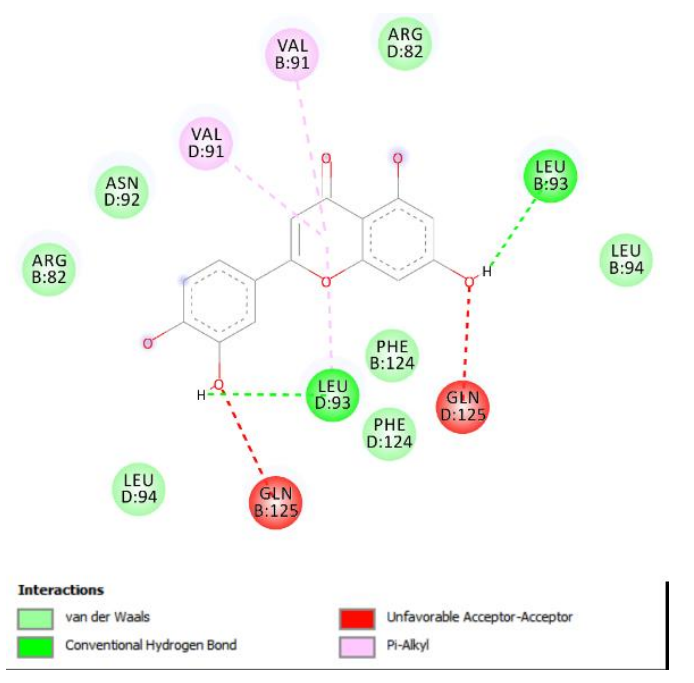

(c)

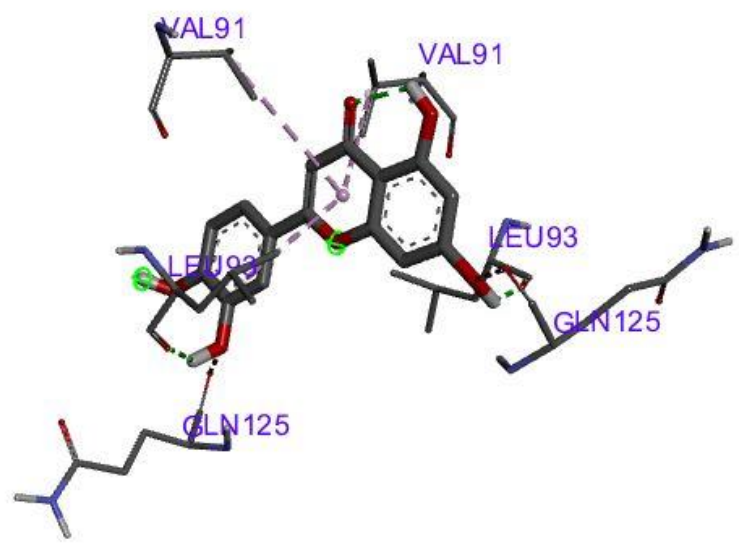

(d)

Figure 16. Molecular interaction between TNF- $\alpha$ with (a) Isoetin 2D; (b) Isoetin 3D; (c) Luteolin 2D; (d) Luteolin 3D.

\subsubsection{IL-1 $\beta$.}

The interaction of IL-1 $\beta$ and donepezil shows a pi-sigma bond with Leu237, pi-pi stacked interaction with Phe150, and pi-alkyl interaction with Pro116. Flavenochromane $\mathrm{C}$ was the only potential ligand that could bind to IL-1 $\beta$. Flavenochromane $\mathrm{C}$ forms hydrogen bonds with Asn108, Met148, and Gln149, pi-anion interaction with Glu105, as well as pi-pi T-shaped interaction with Phe150, and pi- alkyl interaction with Leu201.

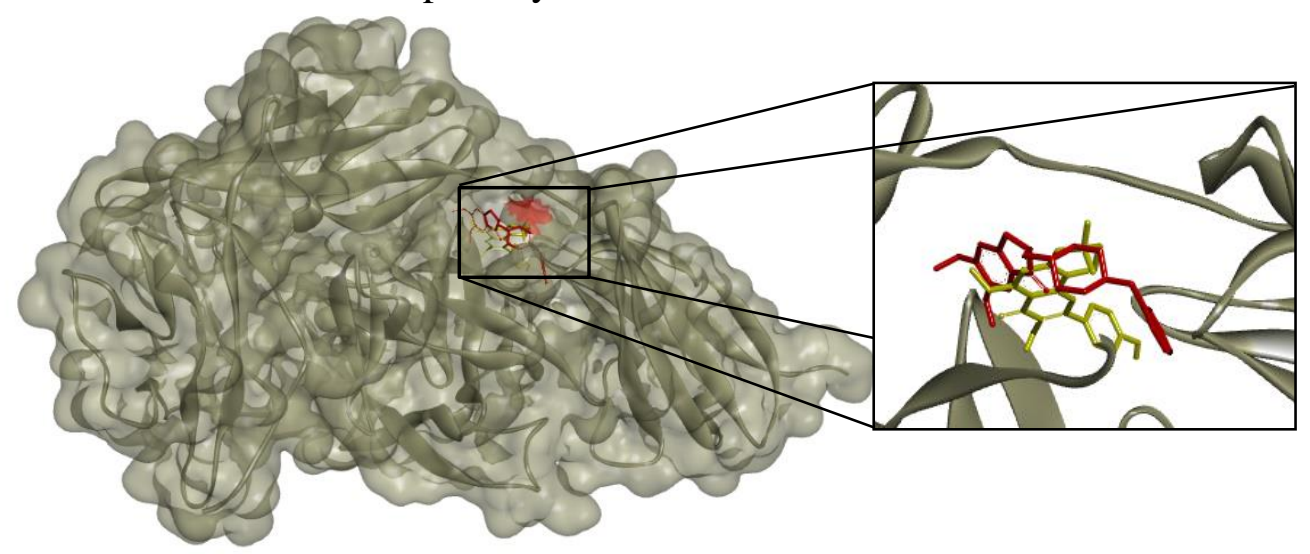

Figure 17. Binding orientation of donepezil(red color) and flavenochromone $\mathrm{C}$ (yellow color) with IL-1 $\beta$.

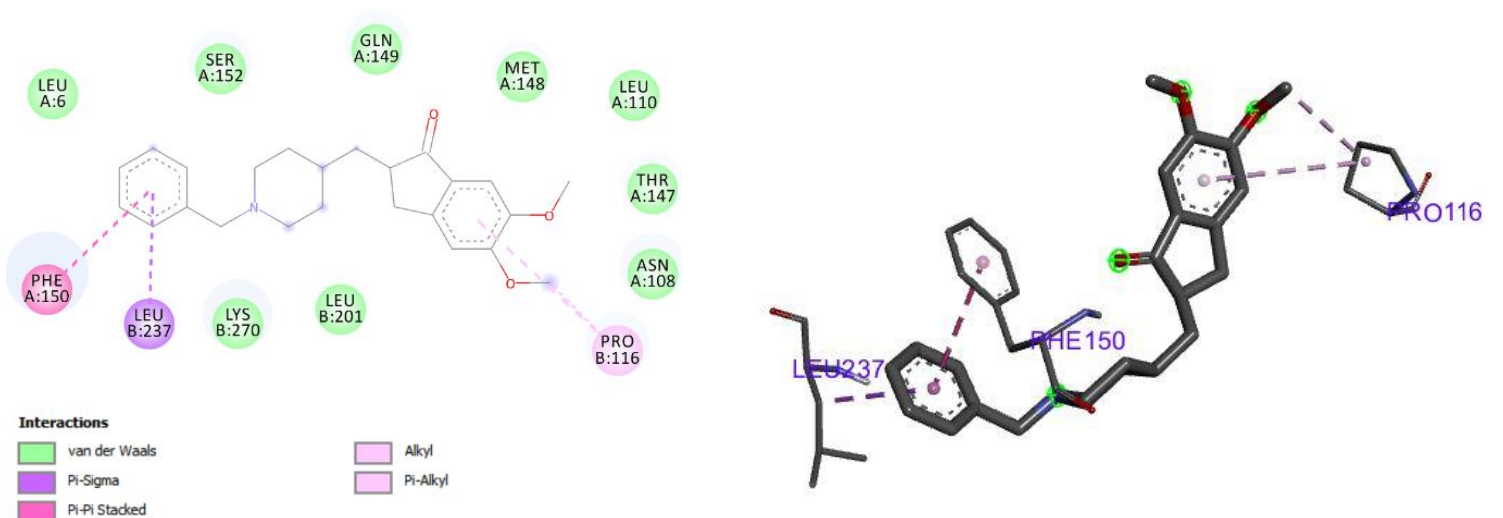

(a)

(b)

Figure 18. Molecular interaction between IL-1 $\beta$ dan donepezil. 


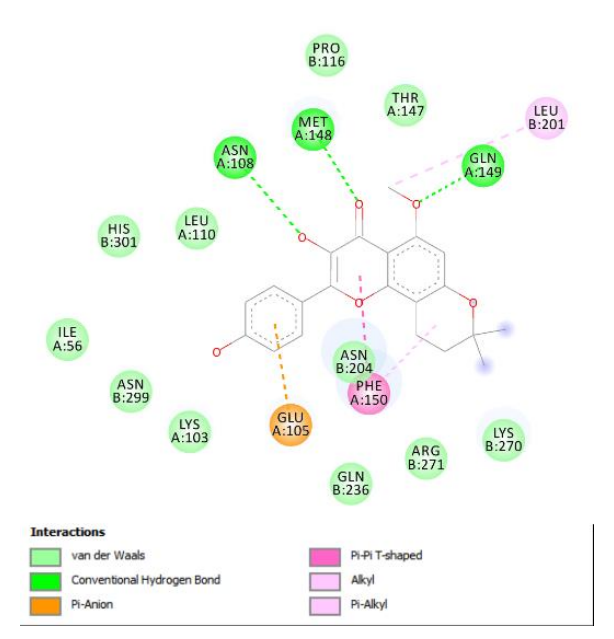

(a)

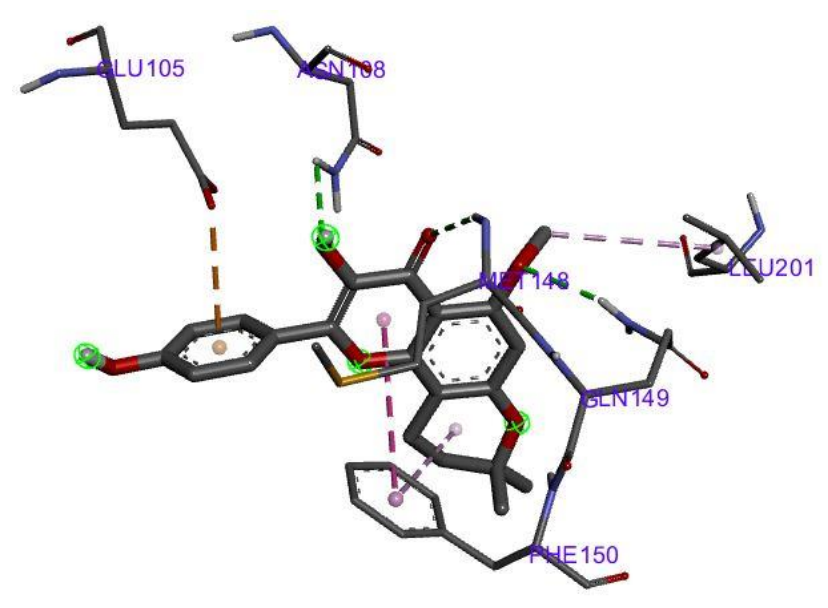

(b)

Figure 19. Molecular interaction between IL-1 $\beta$ and (a) Flavenochromane C 2D; (b) Flavenochromane C 3D.

\subsection{ADMET Analysis.}

Table 5 shows the ADME and toxicity result of six potential propolis compounds with the lowest binding affinity to the targets as neuroprotective agents. All compounds passed the MW, MR, TPSA, lipophilicity, solubility, gastrointestinal absorption, Lipinski violation, and bioavailability properties. However, there are three ligands: Flavenochromane C; 3,4',5Trihydroxy-7-methoxy-8-isopentenyl flavone; and Icaritin were predicted as toxic compounds because their LD50 Acute toxicity is less than $500 \mathrm{mg} / \mathrm{kg}$. Meanwhile, only three ligands for the $\mathrm{BBB}$ category can pass the blood-brain barrier: 5,7,8,3',4'-Pentamethoxy flavone, Flavenochromane C, and Isoetin.

Table 5. ADME and Toxicity properties of potential compounds.

\begin{tabular}{|c|c|c|c|c|c|c|c|c|c|c|}
\hline $\begin{array}{l}\text { Ligand } \\
\text { Name }\end{array}$ & $\underset{1}{\text { MW }}$ & $\mathbf{M R}^{2}$ & $\begin{array}{c}\text { TPS } \\
\mathbf{A}^{3}\end{array}$ & $\begin{array}{c}\text { XLOGP } \\
\mathbf{3}^{4}\end{array}$ & $\begin{array}{c}\text { ESO } \\
\mathbf{L} \\
\mathbf{L o g} \\
\mathbf{S}^{5} \\
\end{array}$ & $\begin{array}{c}\text { GI } \\
\underset{n^{6}}{\operatorname{absorptio}}\end{array}$ & $\begin{array}{c}\text { Lipinski } \\
\text { \#violatio } \\
\text { ns }^{7}\end{array}$ & $\begin{array}{c}\text { Bioavailability } \\
\text { Score }^{8}\end{array}$ & $\begin{array}{l}\mathrm{LD50}^{9} \\
\mathrm{mg} / \mathrm{kg}\end{array}$ & $\begin{array}{c}\text { BBB } \\
\text { Category }^{1}\end{array}$ \\
\hline $\begin{array}{l}5,7,8,3^{\prime}, 4^{\prime}- \\
\text { Pentametho } \\
\text { xy flavone }\end{array}$ & $\begin{array}{c}302 . \\
24\end{array}$ & $\begin{array}{c}78.0 \\
4\end{array}$ & $\begin{array}{c}131.3 \\
6\end{array}$ & 2.17 & -3.55 & High & 0 & 0.55 & 675.075 & 1 \\
\hline Isoetin & $\begin{array}{c}302 . \\
24\end{array}$ & $\begin{array}{c}78.0 \\
3 \\
\end{array}$ & $\begin{array}{c}131.3 \\
6 \\
\end{array}$ & 2.17 & -3.55 & High & 0 & 0.55 & 695.588 & 1 \\
\hline Morin & $\begin{array}{c}302 . \\
24 \\
\end{array}$ & $\begin{array}{c}78.0 \\
3 \\
\end{array}$ & $\begin{array}{c}131.3 \\
6 \\
\end{array}$ & 1.54 & -3.16 & High & 0 & 0.55 & 664.281 & 0 \\
\hline Robinetin & $\begin{array}{c}302 . \\
24\end{array}$ & $\begin{array}{c}78.0 \\
3 \\
\end{array}$ & $\begin{array}{c}131.3 \\
6 \\
\end{array}$ & 1.61 & -3.20 & High & 0 & 0.55 & 695.588 & 0 \\
\hline Luteolin & $\begin{array}{c}286 . \\
24\end{array}$ & $\begin{array}{c}76.0 \\
1 \\
\end{array}$ & $\begin{array}{c}111.1 \\
3 \\
\end{array}$ & 2.53 & -3.71 & High & 0 & 0.55 & 737.446 & 0 \\
\hline $\begin{array}{c}\text { Flavenochro } \\
\text { mane C }\end{array}$ & $\begin{array}{c}368 . \\
38 \\
\end{array}$ & $\begin{array}{c}102 . \\
26\end{array}$ & 89.13 & 3.63 & -4.72 & High & 0 & 0.55 & 346.175 & 1 \\
\hline $\begin{array}{c}3,4^{\prime}, 5- \\
\text { Trihydroxy- } \\
\text { 7-methoxy- } \\
\text { 8- } \\
\text { isopentenyl } \\
\text { flavone }\end{array}$ & $\begin{array}{c}368 . \\
38\end{array}$ & $\begin{array}{c}104 . \\
20\end{array}$ & $\begin{array}{c}100.1 \\
3\end{array}$ & 4.77 & -5.30 & High & 0 & 0.55 & 253.102 & 0 \\
\hline Icaritin & $\begin{array}{c}368 . \\
38\end{array}$ & $\begin{array}{c}104 . \\
20\end{array}$ & $\begin{array}{c}100.1 \\
3\end{array}$ & 4.77 & -5.30 & High & 0 & 0.55 & 269.958 & 0 \\
\hline
\end{tabular}

${ }^{1}$ Molecular Weight (150-500 g/mol); ${ }^{2}$ Molecular Refractory (40-130); ${ }^{3}$ Topological Polar Surface Area (20 140 Å2); ${ }^{4}$ XLOGP3 (-0.7 - +6.0); ${ }^{5}$ ESOL Log S (<=6); ${ }^{6}$ GI absorption (High); ${ }^{7}$ Lipinski Violations (0, $\max$ $1) ;{ }^{8}$ Bioavailability score (0.55); ${ }^{9}$ LD50 (500-5000); ${ }^{10}$ Blood Brain Barrier (category 1$)$. 


\section{Discussion}

The docking in this study used standard drugs for each target to compare the inhibitory action of propolis compounds. Potential propolis compounds for neuroprotective were chosen by a better binding affinity on the active site of protein than the standard drug. The more negative binding affinity $(\Delta \mathrm{G})$ indicates good stability between protein-ligand at the active site, resulting in a strong bonding form and thermodynamically preferable [40]. Further identification of key active residues of each protein's binding site was made by investigating the molecular interaction of the ligands with the lowest binding affinity value. The interaction of ligands to the protein's binding site was compared to the positive control (drugs). Based on docking results, 18 of 22 propolis compounds have potential binding affinity to act as inhibitors for neurodegenerative related proteins. These potential propolis compounds have lower binding energy than positive controls (including Alzheimer's disease drug of donepezil).

Acetylcholinesterase (AChE) inhibitors are still currently an established treatment for Alzheimer's disease, such as donepezil. However, acetylcholinesterase inhibitors are not a cure. These drugs can reduce neuropsychiatric symptoms and represent a rational therapeutic approach to treating Alzheimer's Disease [41]. Besides, donepezil had common adverse effects like nausea, vomiting, diarrhea, muscle pain, and sleep problems (insomnia). Natural phytocompounds of propolis can be safer than chemical drugs and have fewer side effects. This natural compound can act on multiple targets involved in the diseases.

Docking result shows that molecular interaction of isoetin to AChE forms hydrogen bonds with amino acids residue: Glu202, Ser203, Tyr341, and Tyr337. In addition, donepezil only forms one hydrogen bond to Phe295. Both isoetin and donepezil have a similar bond in the binding site of AChE, namely a stacked pi-pi bond with Trp86. While for Tyr341 residue, donepezil and isoetin form different pi alkyl and hydrogen bonds, respectively. These amino acids residue (Tyr341, Trp86, Phe 295) were observed in the active site of recombinant human AChE. The AChE active site is composed of an anionic site, catalytic site, and acyl pocket [42].

Donepezil can also act directly on microglial cells to inhibit their inflammatory activation (including suppressed TNF- $\alpha$ ) as a neuroprotective effect [43]. Isoetin has the lowest binding affinity to TNF- $\alpha(-9,1 \mathrm{kcal} / \mathrm{mol})$ followed by luteolin $(-8,9 \mathrm{kcal} / \mathrm{mol})$ due to the pi-pi T-shaped bond that occurs in the interaction of isoetin with TNF- $\alpha$. The pi-pi T-shape bond significantly affects the binding affinity value because of their electrostatic, dispersion, and induction contributions. The electron cloud in the aromatic ring of the ligand interacts with key residue in the T-shaped position [44]. Hydrogen bonds have a more significant effect on the stability of ligan-protein interaction, and two hydrogen bonds are found in the binding site of luteolin and TNF- $\alpha$. Based on the docking result, isoetin and luteolin were the best candidate for propolis compounds for TNF- $\alpha$ inhibitor. There was also considerable interest in developing efficient NF-kB inhibitors for neurodegenerative diseases. [45] Molecular interaction showed that isoetin and 5,7,8,3',4'-pentamethoxy flavone formed pi-anion bonds with Glu341 and pi-alkyl interaction with Lys52 in the binding site of NF-kB. It was also observed that Lys52 forms pi-alkyl interaction in donepezil to NF-KB. Donepezil, as a standard drug for Alzheimer's disease, can directly inhibit microglial activation induced by AbetaO through blocking MAPK and NF-kB signaling [46]. The reduced levels of pro-inflammatory cytokines have become an important part of the study of finding the best neuroprotective agent [47-50]. Pro-inflammatory cytokines of NF-kB and TNF- $\alpha$ are known as neuroinflammatory 
markers [50]. NF-kB interacts with transcriptional coactivator CREB binding protein (CBP) and promotes more transcription of various pro-inflammatory genes. NF-kB is the main transcription factor responsible for promoting the transcription of inflammatory mediators [49, $51,52]$. While, TNF- $\alpha$ has become the preferred pro-inflammatory target in neuroprotection $[47,50]$. Thus, inhibition of NF-kB and TNF- $\alpha$ is expected.

Reale, M (2005) reported an increase of IL-1 $\beta$ secretion in Alzheimer patients compared to healthy controls, and donepezil can decrease the cytokine level after 1 month of treatment [53]. Our study showed that flavenochromane $\mathrm{C}$ was identified as a potential IL-1 $\beta$ inhibitor based on docking results and binding energy. Flavenochromane $\mathrm{C}$ formed three hydrogen bonds with Asn108, Met148, Gln149 and also formed a pi-anion bond with Glu A:105, pi-pi T-shaped bond with Phe150, and pi-alkyl bond with Leu201. A large number of hydrogen bonding factors, the pi-anion, pi-pi T-shaped bond, and pi-alkyl bonds, help the ligands maintain their conformation to be more stable.

P38 mitogen-activated protein kinase (MAPK14) has been reported by Fernandes et al. (2018) as an important target for proposing a neuroprotective agent. P38 MAPK was an important downstream cascade involved in glial cell activation and neuroinflammation [54]. Fostamatinib is used as a standard based on its inhibitory action to p38 MAPK [55]. Fostamatinib form 4 hydrogen bonds, while the potential ligands of propolis (Robinetin and 3,4',5-Trihydroxy-7-methoxy-8-isopentenyl flavone) form more than 4 hydrogen bonds. Hydrophobic bonds (pi-alkyl and alkyl) and electrostatic bonds (van der Waals) were also observed in the interaction of potential ligands with MAPK14. Molecular interaction analysis shows that Leu167 always appears in the binding site interaction of MAPK14. Michelotti et al. (2005) reported that Leu167 was found in the hydrophobic pocket of p38 $\alpha$ MAP kinase (MAPK14) and bound to the diphenyl ether moiety of ATP-competitive inhibitor form a common binding mode. Leu167 has an important role in the ATP-binding site of the kinase molecule [56]. Therefore, it can be predicted that propolis compounds have better inhibition to p38 MAPK than fostamatinib.

Saif Khan et al. (2015) reported that Caspase 3 is involved in the regulation of multineurodegenerative disorders, namely, Alzheimer's disease (AD), Parkinson's disease (PD), Huntington's disease (HD), and amyotrophic lateral sclerosis (ALS) [57]. Caspase-3 was identified as a key mediator of neuronal apoptosis. In this study, molecular interaction analysis shows that huperzine A, isoetin, and morin formed the same hydrogen bond to Arg 341 in the binding site of caspase 3. While docking results showed that isoetin and morin have lower binding affinity than huperzine A. Huperzine A reported as a neuroprotector that inhibits caspase 3 activity from neuronal apoptosis [58]. Therefore, propolis compounds have potential anti-apoptotic activity induced by caspase 3 . As previously described, caspase-3 plays a role in neuronal-apoptosis as well as the development and progression of neurological disorders. Although these studies are not enough to explain their anti-apoptotic activity, The antioxidant properties of propolis can support the potential effect of anti-apoptotic propolis for further in vitro analysis. Previous studies reported that antioxidant properties support the neuroprotective effect of selected compounds in reducing reactive oxygen species levels as well as the inhibition of active caspase 3 in HT22 cells [59]. Polyphenols and flavonoids content of propolis show good performance of antioxidant activity [60]. These natural antioxidants are key players against oxidative stress, which is considered a lead cause of many neurodegenerative conditions $[61,62]$ 
The selected potential compounds of propolis $\left(5,7,8,3^{\prime}, 4^{\prime}\right.$-pentamethoxy flavone; isoetin; morin; robinetin; luteolin; flavenochromane C; 3,4',5-trihydroxy-7-methoxy-8isopentenyl flavone, and icaritin) were further analyzed for their ADMET properties. Compared with donepezil, Drugbank reported that acute rat LD50 of donepezil was $32.6 \mathrm{mg} / \mathrm{kg}$ while none of potential propolis compounds have LD50 less than $100 \mathrm{mg} / \mathrm{kg}$. Therefore, propolis compounds can be more saver than donepezil. All six potential propolis compounds passed all ADME properties. However, only three compounds could pass the blood-brain barrier (BBB) permeation parameter, namely isoetin; 5,7,8,3',4'-pentamethoxy flavone; and flavenochromane C. Neuroprotective agent that has good permeation through BBB may give an efficient therapeutic effect. BBB is a physiological structure of blood vessels that regulates the entrance and discharge of ions and molecules between blood and brain tissue. BBB provides a natural shield against toxins and restricts the access of molecules into the brain. So, it can limit the brain's uptake of therapeutic agents [63-65]. Therefore, a therapeutic agent for neurodegenerative diseases must pass the blood-brain barrier for efficient efficacy.

\section{Conclusions}

In this study, 18 propolis compounds were identified as potential inhibitors for protein targets involved in neurodegenerative diseases based on molecular docking simulation. The potential compounds of propolis show better binding affinity than standard drugs, and it can be more saver than donepezil. For AChE, only isoetin has a lower binding affinity than donepezil. Isoetin also potentially inhibit the Caspase3, MAPK14, NF-kB, TNF- $\alpha$ and it was better than donepezil, fostamatinib and huperzine A. In silico prediction of blood-brain barrier permeant revealed that only three propolis compounds could pass the BBB, they are isoetin; $5,7,8,3^{\prime}, 4^{\prime}-$ pentamethoxy flavone; and flavenochromane C. 5,7,8,3',4'-pentamethoxy flavone can strongly bind to NF-kB and TNF- $\alpha$. Furthermore, Flavenochromane $\mathrm{C}$ potentially inhibits MAPK14, NF-kB, TNF- $\alpha$ better than standard drugs. These three compounds are firstly reported as neuroprotective agents. Therefore, these compounds can be further explored and could be used as a backbone molecule to develop new treatments for neurodegenerative diseases.

\section{Funding}

This research received no external funding.

\section{Acknowledgments}

We thank PT Nano Herbaltama Internasional for providing propolis.

\section{Conflicts of Interest}

The authors declare no conflict of interest.

\section{References}

1. Hung, C.W.; Chen, Y.C.; Hsieh, W.L.; Chiou, S.H.; Kao, C.L. Ageing and Neurodegenerative Diseases. Ageing Res. Rev. 2010, 9, S36-S46, https://doi.org/10.1016/j.arr.2010.08.006.

2. Olesen, J.; Gustavsson, A.; Svensson, M.; Wittchen, H.U.; Jönsson, B. The Economic Cost of Brain Disorders in Europe. Eur. J. Neurol. 2012, 19, 155-162, https://doi.org/10.1111/j.1468-1331.2011.03590.x.

3. Of, A.M. Dementia in the Asia Pacific Region: The Epidemic Is Here. Acta Neurol. Taiwan 2007, 16, 183187.

4. Fischer, R.; Maier, O. Interrelation of Oxidative Stress and Inflammation in Neurodegenerative Disease: 
Role of TNF. Oxid. Med. Cell. Longev. 2015, 2015, https://doi.org/10.1155/2015/610813.

5. Dunn, N.R.; Pearce, G.L.; Shakir, S.A.W. Adverse Effects Associated with the Use of Donepezil in General Practice in England 2000, 14, 406-408.

6. Hashimoto, M.; Imamura, T.; Tanimukai, S. Urinary Incontinence: An Unrecognised Adverse Effect with Donepezil. Lancet 2000, 356, 568.

7. Carrasco, M.M.; Agüera, L.; Gil, P.; Morínigo, A.; Leon, T. Safety and Effectiveness of Donepezil on Behavioral Symptoms in Patients with Alzheimer Disease. Alzheimer Dis. Assoc. Disord. 2011, 25, 333340, https://doi.org/10.1097/WAD.0b013e318212ab7a.

8. Li, H. C.; Luo, K.X.; Wang, J.S.; Wang, Q.X. Extrapyramidal Side Effect of Donepezil Hydrochloride in an Elderly Patient: A Case Report. Medicine (Baltimore) 2020, 99, e19443, https://doi.org/10.1097/MD.0000000000019443.

9. Wang, J.; Song, Y.; Chen, Z.; Leng, S.X. Connection between Systemic Inflammation and Neuroinflammation Underlies Neuroprotective Mechanism of Several Phytochemicals in Neurodegenerative Diseases. Oxid. Med. Cell. Longev. 2018, 2018, https://doi.org/10.1155/2018/1972714.

10. Uddin, M.S.; Al Mamun, A.; Kabir, M.T.; Ahmad, J.; Jeandet, P.; Sarwar, M.S.; Ashraf, G.M.; Aleya, L. Neuroprotective Role of Polyphenols against Oxidative Stress-Mediated Neurodegeneration. Eur. J. Pharmacol. 2020, 886, 173412, https://doi.org/10.1016/j.ejphar.2020.173412.

11. Uddin, M.S.; Hossain, M.F.; Mamun, A.A.; Shah, M.A.; Hasana, S.; Bulbul, I.J.; Sarwar, M.S.; Mansouri, R.A.; Ashraf, G.M.; Rauf, A.; Abdel-Daim, M.M.; Bin-Jumah, M.N. Exploring the Multimodal Role of Phyzochemicals in the Modulation of Cellular Signaling Pathways to Combat Age-Related Neurodegeneration. Sci. Total Environ. 2020, 725, 138313, https://doi.org/10.1016/j.scitotenv.2020.138313.

12. Kumar, G.; Patnaik, R. Exploring Neuroprotective Potential of Withania Somnifera Phytochemicals by Inhibition of GluN2B-Containing NMDA Receptors: An in Silico Study. Med. Hypotheses 2016, 92, 35-43, https://doi.org/10.1016/j.mehy.2016.04.034.

13. Mazumder, M.K.; Choudhury, S.; Borah, A. An in Silico Investigation on the Inhibitory Potential of the Constituents of Pomegranate Juice on Antioxidant Defense Mechanism: Relevance to Neurodegenerative Diseases. IBRO Reports 2019, 6, 153-159, https://doi.org/10.1016/j.ibror.2019.05.003.

14. Rai, S. N.; Mishra, D.; Singh, P.; Vamanu, E.; Singh, M. P. Therapeutic Applications of Mushrooms and Their Biomolecules along with a Glimpse of in Silico Approach in Neurodegenerative Diseases. Biomed. Pharmacother 2021, 137, 111377, https://doi.org/10.1016/j.biopha.2021.111377.

15. Eberini, I.; Daniele, S.; Parravicini, C.; Sensi, C.; Trincavelli, M.L.; Martini, C.; Abbracchio, M.P. In Silico Identification of New Ligands for GPR17: A Promising Therapeutic Target for Neurodegenerative Diseases. J. Comput. Aided. Mol. Des. 2011, 25, 743-752, https://doi.org/10.1007/s10822-011-9455-8.

16. Ivanova, L.; Karelson, M.; Dobchev, D.A. Identification of Natural Compounds against Neurodegenerative Diseases Using in Silico Techniques. Molecules 2018, 23, https://doi.org/10.3390/molecules23081847.

17. Asih, P.R.; Prikas, E.; Stefanoska, K.; Tan, A.R.P.; Ahel, H.I.; Ittner, A. Functions of P38 MAP Kinases in the Central Nervous System. Front. Mol. Neurosci. 2020, 13, 1-27, https://doi.org/10.3389/fnmol.2020.570586.

18. McAlpine, F.E.; Tansey, M.G. Neuroinflammation and Tumor Necrosis Factor Signaling in the Pathophysiology of Alzheimer's Disease. J. Inflamm. Res. 2008, 1, 29-39.

19. Olmos, G.; Lladó, J. Tumor Necrosis Factor Alpha: A Link between Neuroinflammation and Excitotoxicity. Mediators Inflamm. 2014, 2014, https://doi.org/10.1155/2014/861231.

20. Shaftel, S.S.; Griffin, W.S.T.; Kerry, K.M. The Role of Interleukin-1 in Neuroinflammation and Alzheimer Disease: An Evolving Perspective. J. Neuroinflammation 2008, 5, 1-12, https://doi.org/10.1186/1742-20945-7.

21. Kempuraj, D.; Thangavel, R.; Natteru, P. A.; Selvakumar, G. P.; Saeed, D.; Zahoor, H.; Zaheer, S.; Iyer, S. S.; Zaheer, A. Neuroinflammation Induces Neurodegeneration. J. Neurol. Neurosurg. spine 2016, 1, 1-15.

22. D'Amelio, M.; Cavallucci, V.; Middei, S.; Marchetti, C.; Pacioni, S.; Ferri, A.; Diamantini, A.; De Zio, D.; Carrara, P.; Battistini, L.; Moreno, S.; Bacci, A.; Ammassari-Teule, M.; Marie, H.; Cecconi, F. Caspase-3 Triggers Early Synaptic Dysfunction in a Mouse Model of Alzheimer's Disease. Nat. Neurosci. 2011, 14, 69-79, https://doi.org/10.1038/nn.2709.

23. Talesa, V.N. Acetylcholinesterase in Alzheimer's Disease. Mech. Ageing Dev. 2001, 122, 1961-1969, https://doi.org/10.1016/S0047-6374(01)00309-8.

24. Molan, P. Why Honey Is Effective as a Medicine: 2. The Scientific Explanation of Its Effects. Bee World 2001, 82, 22-40, https://doi.org/10.1080/0005772X.2001.11099498.

25. Farooqui, T.; A. Farooqui, A. Molecular Mechanism Underlying the Therapeutic Activities of Propolis: A Critical Review. Curr. Nutr. Food Sci. 2010, 6, 186-199, https://doi.org/10.2174/157340110792389136.

26. Altuğ, M.E.; Serarslan, Y.; Bal, R.; Kontaş, T.; Ekici, F.; Melek, I.M.; Aslan, H.; Duman, T. Caffeic Acid Phenethyl Ester Protects Rabbit Brains against Permanent Focal Ischemia by Antioxidant Action: A Biochemical and Planimetric Study. Brain Res. 2008, 1201, 135-142, https://doi.org/10.1016/j.brainres.2008.01.053.

27. Choi, D.; Han, J.; Lee, Y.; Choi, J.; Han, S.; Hong, S.; Jeon, H.; Kim, Y. M.; Jung, Y. Caffeic Acid Phenethyl Ester Is a Potent Inhibitor of HIF Prolyl Hydroxylase: Structural Analysis and Pharmacological Implication. 
J. Nutr. Biochem. 2010, 21, 809-817, https://doi.org/10.1016/j.jnutbio.2009.06.002.

28. Wei, X.; Ma, Z.; Fontanilla, C.V.; Zhao, L.; Xu, Z.C.; Taggliabraci, V.; Johnstone, B.H.; Dodel, R.C.; Farlow, M.R.; Du, Y. Caffeic Acid Phenethyl Ester Prevents Cerebellar Granule Neurons (CGNs) against Glutamate-Induced Neurotoxicity. Neuroscience 2008, 155, 1098-1105, https://doi.org/10.1016/j.neuroscience.2008.06.056.

29. Wu, Z.; Zhu, A.; Takayama, F.; Okada, R.; Liu, Y.; Harada, Y.; Wu, S.; Nakanishi, H. Brazilian Green Propolis Suppresses the Hypoxia-Induced Neuroinflammatory Responses by Inhibiting NF- B Activation in Microglia. Oxid. Med. Cell. Longev. 2013, 2013, https://doi.org/10.1155/2013/906726.

30. Swamy, M.; Suhaili, D.; Sirajudeen, K.N.S.; Mustapha, Z.; Govindasamy, C. Propolis Ameliorates Tumor Nerosis Factor- $\alpha$, Nitric Oxide Levels, Caspase-3 and Nitric Oxide Synthase Activities in Kainic Acid Mediated Excitotoxicity in Rat Brain. African J. Tradit. Complement. Altern. Med. 2014, 11, 48-53, https://doi.org/10.4314/ajtcam.v11i5.8.

31. Noelker, C.; Bacher, M.; Gocke, P.; Wei, X.; Klockgether, T.; Du, Y.; Dodel, R. The Flavanoide Caffeic Acid Phenethyl Ester Blocks 6-Hydroxydopamine- Induced Neurotoxicity. Neurosci. Lett. 2005, 383, 3943, https://doi.org/10.1016/j.neulet.2005.04.023.

32. Barros Silva, R.; Santos, N.A.G.; Martins, N.M.; Ferreira, D.A.S.; Barbosa, F.; Oliveira Souza, V.C.; Kinoshita, Â.; Baffa, O.; Del-Bel, E.; Santos, A. C. Caffeic Acid Phenethyl Ester Protects against the Dopaminergic Neuronal Loss Induced by 6-Hydroxydopamine in Rats. Neuroscience 2013, 233, 86-94, https://doi.org/10.1016/j.neuroscience.2012.12.041.

33. Ha, S.K.; Moon, E.; Kim, S.Y. Chrysin Suppresses LPS-Stimulated Proinflammatory Responses by Blocking NF-KB and JNK Activations in Microglia Cells. Neurosci. Lett. 2010, 485, 143-147, https://doi.org/10.1016/j.neulet.2010.08.064.

34. Chen, J.; Long, Y.; Han, M.; Wang, T.; Chen, Q.; Wang, R. Water-Soluble Derivative of Propolis Mitigates Scopolamine-Induced Learning and Memory Impairment in Mice. Pharmacol. Biochem. Behav. 2008, 90, 441-446, https://doi.org/10.1016/j.pbb.2008.03.029.

35. Takashima, M.; Ichihara, K.; Hirata, Y. Neuroprotective Effects of Brazilian Green Propolis on Oxytosis/Ferroptosis in Mouse Hippocampal HT22 Cells. Food Chem. Toxicol. 2019, 132, 110669 , https://doi.org/10.1016/j.fct.2019.110669.

36. Chen, H.Q.; Jin, Z.Y.; Wang, X.J.; Xu, X.M.; Deng, L.; Zhao, J.W. Luteolin Protects Dopaminergic Neurons from Inflammation-Induced Injury through Inhibition of Microglial Activation. Neurosci. Lett. 2008, 448, 175-179, https://doi.org/10.1016/j.neulet.2008.10.046.

37. Nanaware, S.; Shelar, M.; Sinnathambi, A.; Mahadik, K. R.; Lohidasan, S. Neuroprotective Effect of Indian Propolis in $\beta$-Amyloid Induced Memory Deficit: Impact on Behavioral and Biochemical Parameters in Rats. Biomed. Pharmacother 2017, 93, 543-553, https://doi.org/10.1016/j.biopha.2017.06.072.

38. Hanif, A.; Nurdiansyah, R.; Hawa, P.; Wahyu, D.; Eko, K.; Dwi, C.; Taufiqu, N.; Novan, N.; Noviyanto, A.; Mardliyati, E. In Silico Investigation of Potential Inhibitors to Main Protease and Spike Protein of SARS$\mathrm{CoV}-2$ in Propolis. Biochem. Biophys. Reports 2021, 26, 100969, https://doi.org/10.1016/j.bbrep.2021.100969.

39. Daina, A.; Michielin, O.; Zoete, V. SwissADME: A Free Web Tool to Evaluate Pharmacokinetics, DrugLikeness and Medicinal Chemistry Friendliness of Small Molecules. Sci. Rep. 2017, 7, 1-13, https://doi.org/10.1038/srep42717.

40. Du, X.; Li, Y.; Xia, Y.L.; Ai, S.M.; Liang, J.; Sang, P.; Ji, X.L.; Liu, S.Q. Insights into Protein-Ligand Interactions: Mechanisms, Models, and Methods. Int. J. Mol. Sci. 2016, 17, 1-34, https://doi.org/10.3390/ijms17020144.

41. Ibach, B.; Haen, E. Acetylcholinesterase Inhibition in Alzheimers Disease. Curr. Pharm. Des. 2005, 10, 231-251, https://doi.org/10.2174/1381612043386509.

42. Akhoon, B.A.; Choudhary, S.; Tiwari, H.; Kumar, A.; Barik, M.R.; Rathor, L.; Pandey, R.; Nargotra, A. Discovery of a New Donepezil-like Acetylcholinesterase Inhibitor for Targeting Alzheimer's Disease: Computational Studies with Biological Validation. J. Chem. Inf. Model. 2020, 60, 4717-4729, https://doi.org/10.1021/acs.jcim.0c00496.

43. Hwang, J.; Hwang, H.; Lee, H.W.; Suk, K. Microglia Signaling as a Target of Donepezil. Neuropharmacology 2010, 58, 1122-1129, https://doi.org/10.1016/j.neuropharm.2010.02.003.

44. Sinnokrot, M.O; Sherrill, C.D. Substituent Effects in $\pi-\pi$ Interactions: Sandwich and t-Shaped Configurations. J. Am. Chem. Soc. 2004, 126, 7690-7697, https://doi.org/10.1021/ja049434a.

45. Srinivasan, M.; Lahiri, D.K. Significance of NF-KB as a Pivotal Therapeutic Target in the Neurodegenerative Pathologies of Alzheimer's Disease and Multiple Sclerosis. Expert Opin. Ther. Targets 2015, 19, 471-487, https://doi.org/10.1517/14728222.2014.989834.

46. Kim, H.G.; Moon, M.; Choi, J.G.; Park, G.; Kim, A.J.; Hur, J.; Lee, K.T.; Oh, M.S. Donepezil Inhibits the Amyloid-Beta Oligomer-Induced Microglial Activation in Vitro and in Vivo. Neurotoxicology 2014, 40, 23 32, https://doi.org/10.1016/j.neuro.2013.10.004.

47. Potential, N.; Firdous, A.; Sarwar, S.; Shah, F.A.; Tabasum, S.; Zeb, A.; Nadeem, H.; Alamro, A.; Alghamdi, A. A.; Alvi, A. M.; Naeem, K.; Khalid, M. S. Rosa Webbiana Fruit and Its Chitosan Encapsulation. 2021, $1-15$. 
48. He, D.; Fu, S.; Zhou, A.; Su, Y.; Gao, X.; Zhang, Y.; Huang, B.; Du, J.; Liu, D. Camptothecin Regulates Microglia Polarization and Exerts Neuroprotective Effects via Activating AKT/Nrf2/HO-1 and Inhibiting NF-KB Pathways In Vivo and In Vitro. Front. Immunol. 2021, 12, 1-14, https://doi.org/10.3389/fimmu.2021.619761.

49. Saroj, P.; Bansal, Y.; Singh, R.; Akhtar, A.; Sodhi, R.K.; Bishnoi, M.; Sah, S.P.; Kuhad, A. Neuroprotective Effects of Roflumilast against Quinolinic Acid-Induced Rat Model of Huntington's Disease through Inhibition of NF-KB Mediated Neuroinflammatory Markers and Activation of CAMP/CREB/BDNF Signaling Pathway. Inflammopharmacology 2021, 29, 499-511, https://doi.org/10.1007/s10787-020-007873.

50. Imran, M.; Shah, F.A.; Nadeem, H.; Zeb, A.; Faheem, M.; Naz, S.; Bukhari, A.; Ali, T.; Li, S. Synthesis and Biological Evaluation of Benzimidazole Derivatives as Potential Neuroprotective Agents in an EthanolInduced Rodent Model. ACS Chem. Neurosci. 2021, 12, 489-505, https://doi.org/10.1021/acschemneuro.0c00659.

51. Rocha, N.P.; Ribeiro, F.M.; Furr-Stimming, E.; Teixeira, A. L. Neuroimmunology of Huntington's Disease: Revisiting Evidence from Human Studies. Mediators Inflamm. 2016, 2016, https://doi.org/10.1155/2016/8653132.

52. Hömberg, V.; Huttunen, J. Muscle Tone in Huntington's Disease. J. Neurol. Sci. 1994, 121, 147-154, https://doi.org/10.1016/0022-510X(94)90343-3.

53. Reale, M.; Iarlori, C.; Gambi, F.; Lucci, I.; Salvatore, M.; Gambi, D. Acetylcholinesterase Inhibitors Effects on Oncostatin-M, Interleukin-1 $\beta$ and Interleukin-6 Release from Lymphocytes of Alzheimer's Disease Patients. Exp. Gerontol. 2005, 40, 165-171, https://doi.org/10.1016/j.exger.2004.12.003.

54. Fernandes, V.; Sharma, D.; Kalia, K.; Tiwari, V. Neuroprotective Effects of Silibinin: An in Silico and in Vitro Study. Int. J. Neurosci. 2018, 128, 935-945, https://doi.org/10.1080/00207454.2018.1443926.

55. Rolf, M.G.; Curwen, J.O.; Veldman-Jones, M.; Eberlein, C.; Wang, J.; Harmer, A.; Hellawell, C. J.; Braddock, M. In Vitro Pharmacological Profiling of R406 Identifies Molecular Targets Underlying the Clinical Effects of Fostamatinib. Pharmacol. Res. Perspect. 2015, 3, 1-12, https://doi.org/10.1002/prp2.175.

56. Michelotti, E.L.; Moffett, K.K.; Nguyen, D.; Kelly, M.J.; Shetty, R.; Chai, X.; Northrop, K.; Namboodiri, V.; Campbell, B.; Flynn, G.A.; Fujimoto, T.; Hollinger, F.P.; Bukhtiyarova, M.; Springman, E.B.; Karpusas, M. Two Classes of P38 a MAP Kinase Inhibitors Having a Common Diphenylether Core but Exhibiting Divergent Binding Modes. Bioorganic Med. Chem. Lett. 2005, 15, 5274-5279, https://doi.org/10.1016/j.bmcl.2005.08.038.

57. Khan, S.; Ahmad, K.; Alshammari, E.M.A.; Adnan, M.; Baig, M.H.; Lohani, M.; Somvanshi, P.; Haque, S. Implication of Caspase-3 as a Common Therapeutic Target for Multineurodegenerative Disorders and Its Inhibition Using Nonpeptidyl Natural Compounds. Biomed Res. Int. 2015, 2015, https://doi.org/10.1155/2015/379817.

58. Zhou, J.; Tang, X.C. Huperzine A Attenuates Apoptosis and Mitochondria-Dependent Caspase-3 in Rat Cortical Neurons. FEBS Lett. 2002, 526, 21-25, https://doi.org/10.1016/S0014-5793(02)03107-1.

59. Cancela, S.; Canclini, L.; Mourglia-Ettlin, G.; Hernández, P.; Merlino, A. Neuroprotective Effects of Novel Nitrones: In Vitro and in Silico Studies. Eur. J. Pharmacol. 2020, 871, 172926, https://doi.org/10.1016/j.ejphar.2020.172926.

60. Martinello, M.; Mutinelli, F. Antioxidant Activity in Bee Products: A Review. Antioxidants 2021, 10, 1-42, https://doi.org/10.3390/antiox10010071.

61. El-Hawary, S.S.; Hammam, W.E.; El-Mahdy El-Tantawi, M.; Yassin, N.A.Z.; Kirollos, F.N.; Abdelhameed, M.F.; Abdelfattah, M.A.O.; Wink, M.; Sobeh, M. Apple Leaves and Their Major Secondary Metabolite Phlorizin Exhibit Distinct Neuroprotective Activities: Evidence from in Vivo and in Silico Studies. Arab. J. Chem. 2021, 14, 103188, https://doi.org/10.1016/j.arabjc.2021.103188.

62. Bashandy, S.A.E.; Salama, A.; Fayed, A.H.M.; Omara, E.A.; El-Toumy, S.A.; Salib, J.Y. Protective Effect of Mandarin (CITRUS RETICULATA) Peel Extract on Potassium Dichromate Induced Hepatotoxicity and Nephrotoxicity in Rats. Plant Arch. 2020, 20, 2231-2242.

63. Lesniak, M.S.; Brem, H. Targeted Therapy for Brain Tumours. Nat. Rev. Drug Discov. 2004, 3, 499-508, https://doi.org/10.1038/nrd1414.

64. Cecchelli, R.; Berezowski, V.; Lundquist, S.; Culot, M.; Renftel, M.; Dehouck, M.P.; Fenart, L. Modelling of the Blood - Brain Barrier in Drug Discovery and Development. Nat. Rev. Drug Discov. 2007, 6, 650-661, https://doi.org/10.1038/nrd2368.

65. Thangudu, S.; Cheng, F.Y.; Su, C.H. Advancements in the Blood-Brain Barrier Penetrating Nanoplatforms for Brain Related Disease Diagnostics and Therapeutic Applications. Polymers (Basel) 2020, 12, 1-23, https://doi.org/10.3390/polym12123055. 